\title{
Invited Review \\ Radioactive contaminants in the subsurface: the influence of complexing ligands on trace metal speciation
}

\author{
Wolfgang Hummel \\ Laboratory for Waste Management, Paul Scherrer Institut, Villigen, Switzerland \\ Received 22 May 2007; Accepted 5 December 2007; Published online 8 April 2008 \\ (C) Springer-Verlag 2008
}

\begin{abstract}
Equilibrium thermodynamics is one of the pillars which support safety analyses of repositories for radioactive waste. The research summarized in this review deals with approaches to resolve the problems related to thermodynamic equilibrium constants and solubility of solid phases in the field of radioactive waste management. The results have been obtained at the Paul Scherrer Institut between 1995 and 2005 and comprise the scientific basis of the author's habilitation thesis in the field of nuclear environmental chemistry. The topics are grouped according to three different levels of problem solving strategies: (1) Critical and comprehensive reviews of the available literature, which are necessary in order to establish a reliable chemical thermodynamic database that fulfils the requirements for rigorous modeling of the behavior of the actinides and fission products in the environment. (2) In many case studies involving inorganic and simple organic ligands a serious lack of reliable thermodynamic data is encountered. There, a new modeling approach to estimate the effects of these missing data was applied. This so called "backdoor approach" begins with the question, "What total concentration of a ligand is necessary to significantly influence the speciation, and hence the solubility, of a given trace metal?" (3) In the field of natural organics,
\end{abstract}

Correspondence: Wolfgang Hummel, Laboratory for Waste Management, Paul Scherrer Institut, 5232 Villigen, Switzerland. E-mail: wolfgang.hummel@psi.ch mainly humic and fulvic acids, we face an ill-defined problem concerning the molecular structure of the ligands. There, a pragmatic approach for performance assessment purposes was applied, the "conservative roof" approach, which does not aim to accurately model all experimental data, but allows estimates of maximum effects on metal complexation by humic substances to be calculated.

Keywords Thermodynamics; Metal complexes; Anions; Data base; Radioactive waste.

\section{Introduction}

The modeling of the behavior of hazardous materials under environmental conditions is among the most important applications of natural and technical sciences for the protection of the environment. In order to assess, for example, the safety of a waste deposit, it is essential to be able to predict the eventual dispersion of its hazardous components in the environment (geosphere and biosphere). For hazardous materials stored in the ground or in geological formations, the most probable transport medium is the aqueous phase. An important factor is therefore the quantitative prediction of the reactions that are likely to occur between hazardous waste dissolved or suspended in groundwater, and the surrounding rock material, in order to estimate the quantities of waste that can be transported in the aqueous phase. It is thus essential to know the relative stabilities of the 
compounds and complexes that may form under the relevant conditions. This information is often provided by speciation calculations using chemical thermodynamic data. The local conditions, such as groundwater and rock composition or temperature, may not be constant along the migration paths of hazardous materials, and fundamental thermodynamic data are the indispensable basis for dynamic modeling of the chemical behavior of hazardous waste components.

In the field of radioactive waste management, the hazardous material consists to a large extent of actinides and fission products from nuclear reactors, in addition to lesser amounts from other sources such as waste from medicine, industry, and research facilities. The scientific literature on thermodynamic data, mainly on equilibrium constants and solubility of solid phases in aqueous solution, has been, and still is, contradictory in a number of cases, especially in actinide and transition metal chemistry.

The research presented in this review consists of approaches of the author to resolve the problems related to thermodynamic equilibrium constants and solubility of solid phases in the field of radioactive waste management. The review summarizes results which mainly have been obtained at the Paul Scherrer Institut between 1995 and 2005 and which comprise the scientific basis of the author's habilitation thesis in the field of nuclear environmental chemistry [1].

The results are grouped according to three different levels of problem solving strategies:

(1) Critical and comprehensive reviews of the available literature, which are necessary in order to establish a reliable chemical thermodynamic database that fulfils the requirements for rigorous modeling of the behavior of the actinides and fission products in the environment. This section is entitled "Thermodynamic data: facts and fiction".

(2) In many case studies involving inorganic and simple organic ligands a serious lack of reliable thermodynamic data is encountered. There, a new modeling approach to estimate the effects of these missing data was applied. This so called "backdoor approach" begins with the question, "What total concentration of a ligand is necessary to significantly influence the speciation, and hence the solubility, of a given trace metal?"
(3) In the field of natural organics, mainly humic and fulvic acids, we face an ill-defined problem concerning the molecular structure of the ligands. There, a pragmatic approach for performance assessment purposes has been proposed, the "conservative roof" approach, which does not aim to accurately model all experimental data, but allows estimates of maximum effects on metal complexation by humic substances to be calculated.

However, before the results of these three topics are summarized it seems to be appropriate first to set the stage, which provides the background and reveals the main driving force of the research activities presented in this review: the safety of nuclear waste repositories [2].

\section{Setting the stage: safety of nuclear waste repositories}

\section{Overview of repository concepts}

Worldwide a significant amount of nuclear waste exists today, and will continue to arise in the future. This waste stems from a range of sources, including electricity production in nuclear power plants and applications of radioactive substances in medicine, industry and research. A key principle of radioactive waste management is that the waste must be disposed of in such a way that the safety of man and the environment is ensured. It is widely accepted that one possibility to meet this obligation is to emplace the waste in a carefully sited and well-designed geological repository.

Internationally, a large number of nuclear waste repositories for low-level waste (LLW), low- and intermediate-level waste (L/ILW), and intermediate-level waste (ILW) have been in operation for many years; for example in Finland, France, Germany, Japan, Spain, Sweden, the UK, and the USA. The situation is different for spent fuel (SF) and vitrified high-level waste (HLW) from reprocessing of spent fuel. These waste types are currently in interim storage facilities to allow the radiogenic heat production to decline to such levels that the waste can be disposed of in deep geological repositories so that temperatures stay below specification limits set to ensure the good performance of the engineered barriers (specifically bentonite, a natural 
Table 1 Examples for different repository concepts for SF/HLW

\begin{tabular}{|c|c|c|c|c|c|c|c|}
\hline Country & Organization & Waste & Canister & Buffer & Host rock & Concept & Ref. \\
\hline Belgium & ONDRAF & $\mathrm{SF} / \mathrm{HLW}$ & steel & bentonite & boom clay & horizontal emplacement in tubes & {$[4]$} \\
\hline Finland & POSIVA & $\mathrm{SF}$ & $\begin{array}{l}\text { copper } \\
\text { with steel } \\
\text { insert }\end{array}$ & bentonite & $\begin{array}{l}\text { crystalline } \\
\text { basement }\end{array}$ & $\begin{array}{l}\text { individual vertical boreholes } \\
\text { in the floor of emplacement } \\
\text { tunnels }\end{array}$ & {$[5]$} \\
\hline France & ANDRA & HLW & steel & bentonite & $\begin{array}{l}\text { callovo- } \\
\text { oxfordian clay }\end{array}$ & $\begin{array}{l}\text { short horizontal tunnels } \\
\text { starting from main gallery }\end{array}$ & {$[6]$} \\
\hline Japan & $\mathrm{JNC}$ & HLW & steel & $\begin{array}{l}\text { bentonite- } \\
\text { sand }\end{array}$ & $\begin{array}{l}2 \text { host rocks } \\
\text { considered: } \\
\text { "hard"/"soft", }\end{array}$ & $\begin{array}{l}2 \text { concepts considered: } \\
\text { horizontal/vertical }\end{array}$ & [7] \\
\hline Sweden & SKB & SF & $\begin{array}{l}\text { copper } \\
\text { with steel } \\
\text { insert }\end{array}$ & bentonite & $\begin{array}{l}\text { crystalline } \\
\text { basement }\end{array}$ & $\begin{array}{l}\text { individual vertical } \\
\text { boreholes in the floor of } \\
\text { emplacement tunnels }\end{array}$ & {$[8]$} \\
\hline Switzerland & Nagra & $\begin{array}{l}\mathrm{SF} / \\
\mathrm{HLW} / \mathrm{ILW}\end{array}$ & steel & $\begin{array}{l}\text { SF/HLW: } \\
\text { bentonite } \\
\text { ILW: cement- } \\
\text { based mortar }\end{array}$ & opalinus clay & horizontal emplacement & [9] \\
\hline USA & DoE & SF/HLW & steel & none & tuff & $\begin{array}{l}\text { horizontal emplacement } \\
\text { in host rock above the water } \\
\text { table, use of drip shields }\end{array}$ & {$[10]$} \\
\hline
\end{tabular}

clay-based material that is foreseen in many SF/ HLW repository concepts as a buffer material between the waste canisters and the host rock). Typical required minimal interim storage times are in the order of 40 years. Even though there is no repository for SF or HLW in operation yet, detailed concepts have been developed and refined over the last years, and implementation is well under way in several countries.

A few selected examples for different repository concepts for SF and HLW are given in Table 1. It is beyond the scope of this review to discuss these in detail here; instead, the interested reader is referred to the references given in Table 1. A broader overview of national repository concepts for all waste types is given by Witherspoon and Bodvarsson [3].

As an example, the possible layout for a Swiss deep geological repository for SF/HLW/ILW in Opalinus Clay is shown in Fig. 1. The repository will consist of a tunnel system for SF and HLW and separate tunnels for ILW, with access via a ramp and/or vertical shaft, depending on the repository location and the host rock that is selected.

\section{Safety concept of a geological repository}

The safety concept explains how the repository system provides long-term safety. This usually involves a multi-barrier system where each barrier contributes to safety by providing multiple safetyrelevant functions. For the case of vitrified HLW, this is illustrated in Fig. 2, where the innermost barrier (the solidification matrix) is shown at the top and the outermost barrier (the geosphere with the host rock) is shown at the bottom. For each barrier, the safety-relevant functions are given, and it is indicated by which processes each function operates. Similar functional descriptions of the safety barrier system for SF and long-lived ILW are given in Ref. [9].

Such a repository system provides the following safety functions:

- Isolation of the waste from the human environment: the safety and security of the waste, including fissile material, is ensured by placing it in a repository located deep underground, with all access routes backfilled and sealed, thus isolating it from the human environment and reducing the likelihood of any undesirable intrusion and misapplication of the materials. Furthermore, the absence of any currently recognized and economically viable natural resources and the lack of conflict with future infrastructure projects that can be conceived at present reduce the likelihood of inadvertent human intrusion. Finally, appropriate siting ensures that the site is not prone to disruptive events and to processes unfavourable to long-term stability. 
- Long-term confinement and radioactive decay within the disposal system: much of the activity initially present decays while the wastes are totally contained within the primary waste containers, particularly in the case of SF and HLW, for which the high integrity steel canisters are expected to remain unbroken for at least 10,000 years. Even after the canisters are breached, the stability of the SF and HLW waste forms in the expected environment, the slowness of groundwater flow and a range of geochemical immobilization and retardation processes ensure that radionuclides continue to be largely confined within the engineered barrier system and the immediately surrounding rock, so that further radioactive decay takes place.
- Attenuation of releases to the environment: although complete confinement cannot be provided over all relevant times for all radionuclides, release rates of radionuclides from the waste forms are low, particularly from the stable SF and HLW waste forms. Furthermore, a number of processes attenuate releases during transport towards the surface environment, and limit the concentrations of radionuclides in that environment. These include a) radioactive decay during slow transport through the barrier provided by the host rock and b) the spreading of released radionuclides in time and space by, for example, diffusion, hydrodynamic dispersion, and dilution.

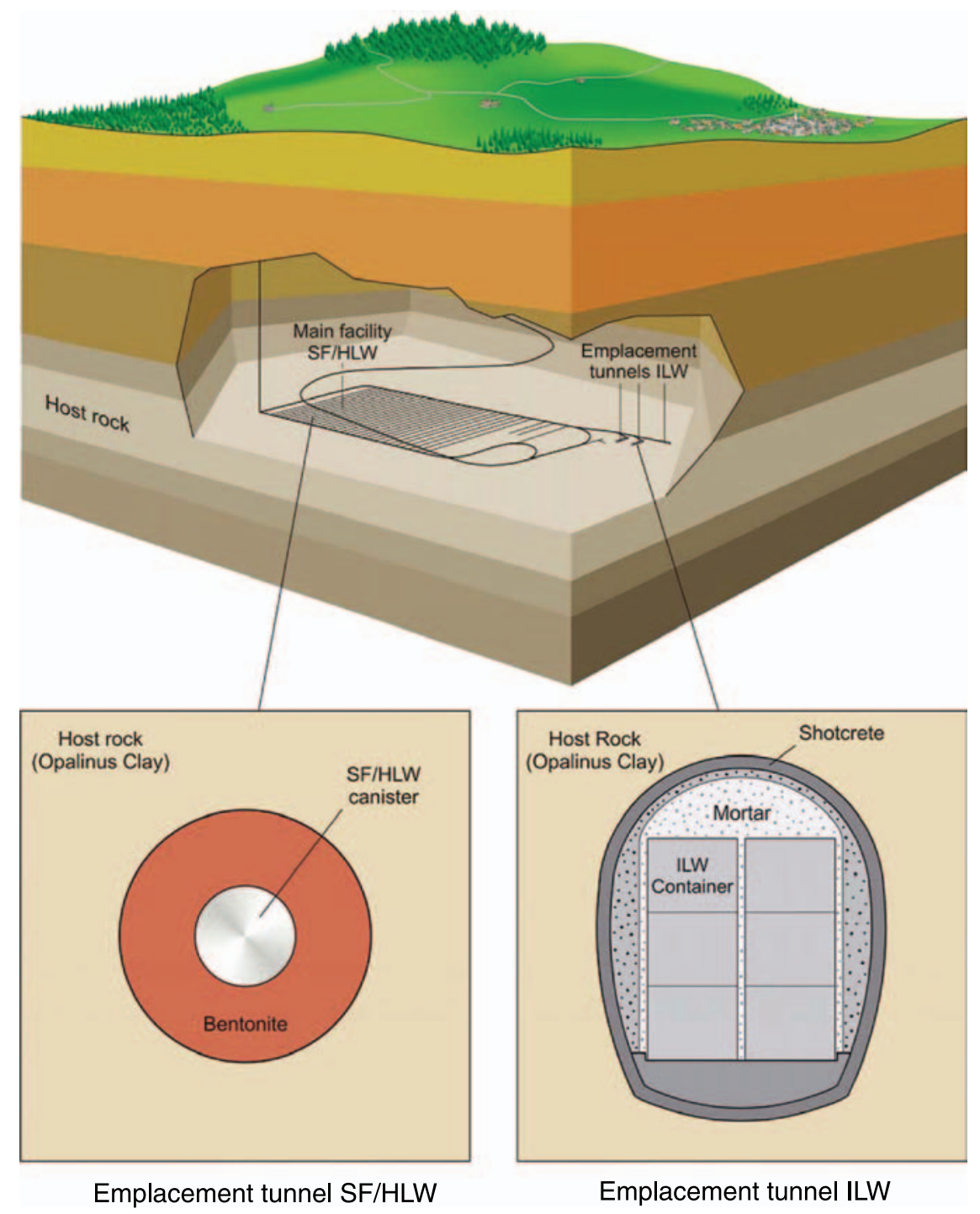

Fig. 1 Possible layout for a deep geological repository for SF/HLW/ILW in Opalinus Clay [9] 


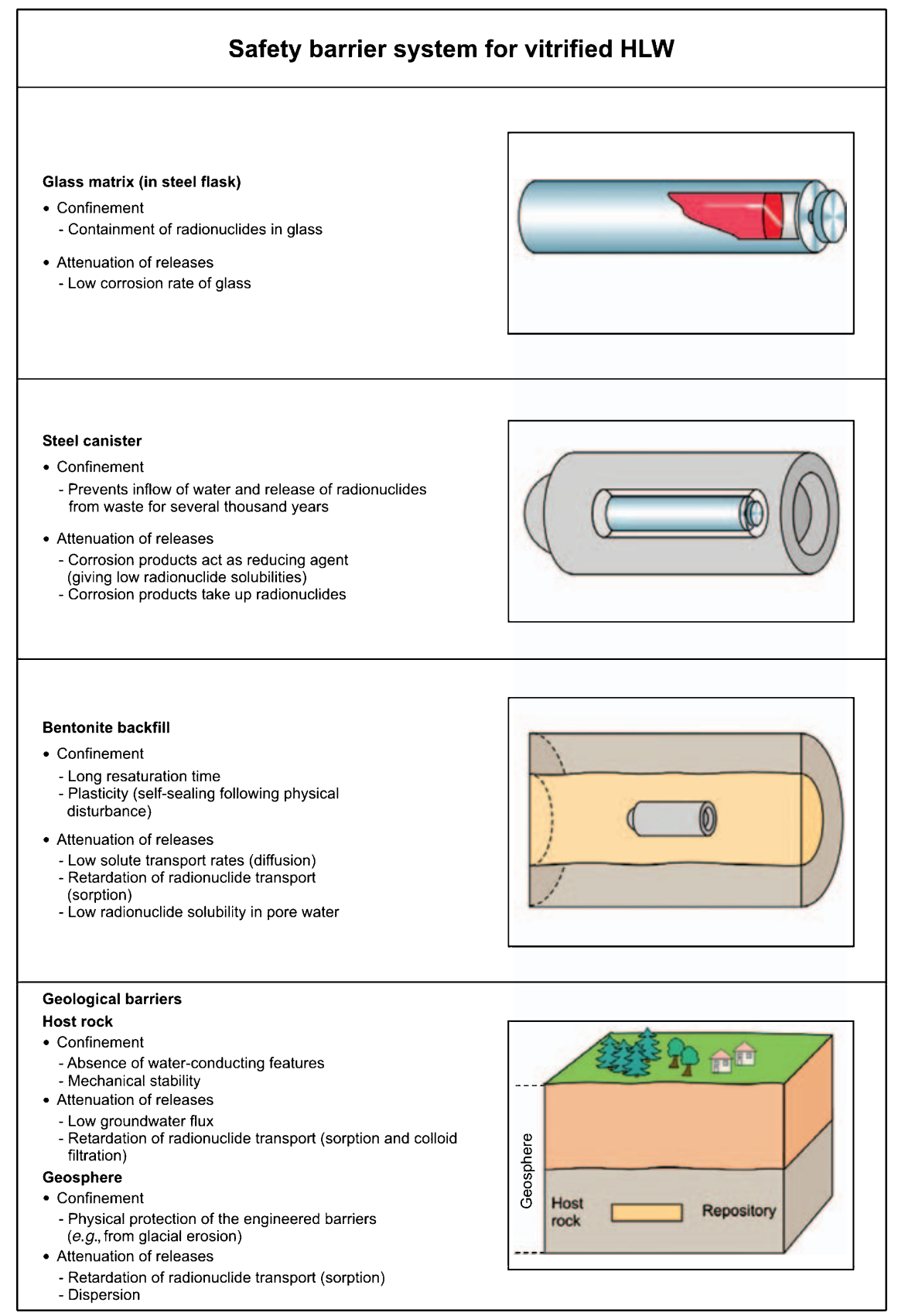

Fig. 2 The system of safety barriers and the multiple safety-relevant functions that each barrier provides in the case of vitrified HLW [9]

\section{Important geochemical parameters and processes for} repository safety

From the viewpoint of (geo)chemistry a number of important parameters and processes have been and still are topics of scientific studies relevant for repository safety. As shown as a graphical summary in Fig. 3, these parameters and processes are:

- Porewater chemistry

- Canister/waste package corrosion
- $\mathrm{SF} / \mathrm{HLW} /$ waste form dissolution with radionuclides entering the aqueous phase

- Solubility limits for radionuclides in the near field and the geosphere

- Diffusion (+ advection) and sorption of radionuclides in the near field

- Diffusion (+ advection) and sorption of radionuclides in the geosphere

In the following, some selected aspects concerning porewater chemistry, solubility limits and sorp- 

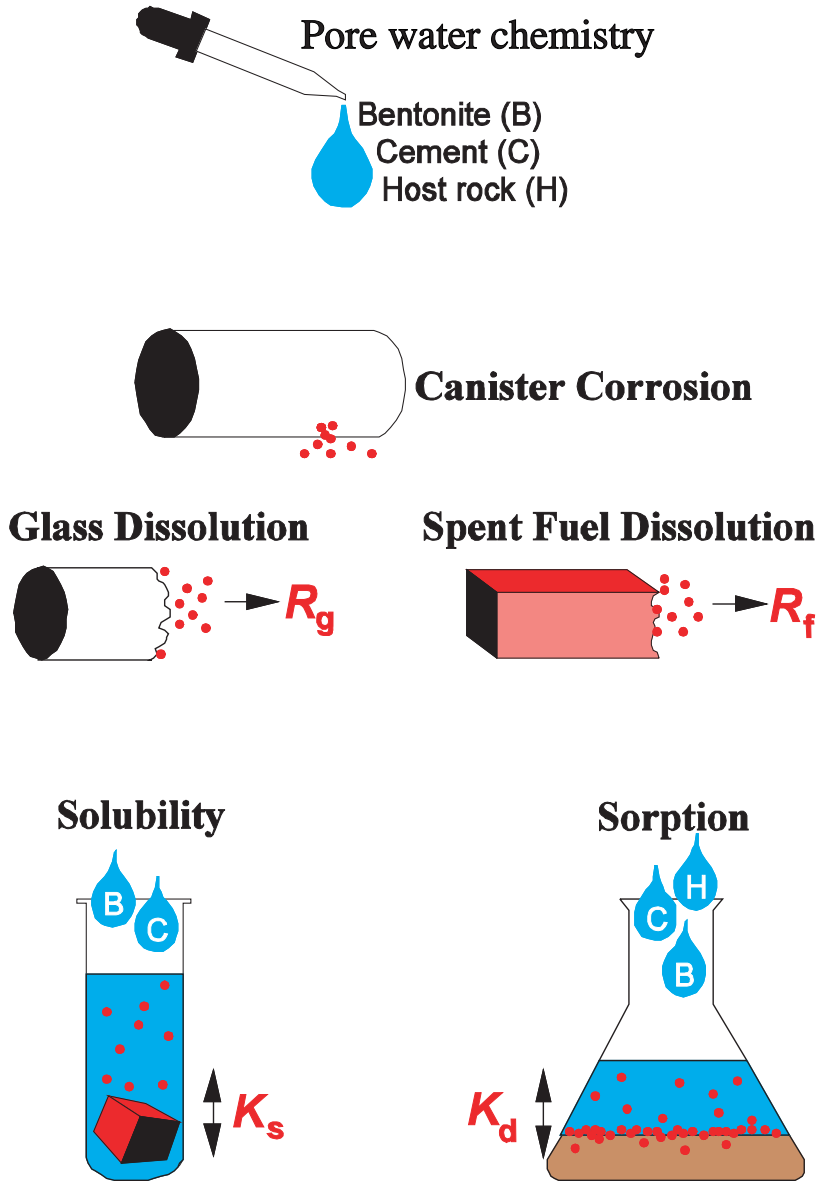

Fig. 3 Important geochemical parameters and processes for repository chemistry. The dissolution parameters $R_{\mathrm{g}}$ and $R_{\mathrm{f}}$ are case specific kinetic rate constants, whereas the elemental solubility limits $K_{\mathrm{s}}$ and the sorption coefficients $K_{\mathrm{d}}$ are element and case specific equilibrium constants

tion are outlined with specific examples. The phenomenon of glass dissolution is discussed by Curti [11].

\section{Porewater chemistry}

Potential repository sites are foreseen in geological formations with low groundwater flow. Specifically, clay host rocks (see Table 1) are characterized by very low groundwater flow. This implies difficulties with respect to the prerequisite of all geochemical modeling for repository safety, i.e., the definition of the porewater chemistry. Whereas sampling and subsequent chemical analyses of surface water, water from wells or groundwater in deep aquifers are routine procedures, the sampling and analysis of porewater in material with a low hydraulic conductivity is an exceedingly difficult task.
If, for example, the water "flow" in the sampling site of a dense clay formation is a few drops per day, there is a high probability that the small quantity of water obtained after several weeks of sampling is no longer identical with the original porewater. The original porewater perhaps is not in thermodynamic equilibrium with carbon dioxide of the atmosphere and hence, either some outgassing of $\mathrm{CO}_{2}$ or dissolution of atmospheric $\mathrm{CO}_{2}$ in the water may occur during the sampling. In both cases not only the carbonate concentration in the sampled water changes but also the $p H$ of the water. These and other sampling artefacts may change the water chemistry of the finally analyzed sample considerably. Similar artefacts are encountered in the attempt to obtain porewater by high-pressure squeezing of rock samples or bentonite backfill material. The latter is provided for most SF/HLW repository concepts (Table 1).

In summary, the definition of porewater chemistry involves the scrutinising of field data, laboratory experiments and geochemical modeling, as discussed in several reports [12-14]. Despite all these efforts some uncertainty in key parameters such as $\mathrm{CO}_{2}$ partial pressure and $p H$ remains and has to be considered in subsequent modeling of solubilities for repository safety purposes.

Recent research activities in the field of molecular modeling aim at an understanding of the properties of water in such highly compacted clay systems on a molecular level with the goal of reducing the uncertainties in the definition of porewaters in these systems.

\section{Solubility limits}

An important feature of repository safety is the fact that radionuclides cannot be dissolved in unlimited quantities in the aqueous phase. Their maximum concentrations are limited by the precipitation of solid phases when the solution becomes oversaturated with respect to a certain radionuclide. These so-called elemental solubility limits, $K_{\mathrm{s}}$, can be calculated by thermodynamic modeling assuming that in the long term chemical equilibrium is reached between solids and the aqueous phase [15].

As an example, the solubility of americium in bentonite porewater [16] is shown in Fig. 4. The above mentioned uncertainty in the $\mathrm{CO}_{2}$ partial pressure of the bentonite reference porewater is reflected in the $\log _{10} p \mathrm{CO}_{2}$ parameter range of Fig. 4. As a 


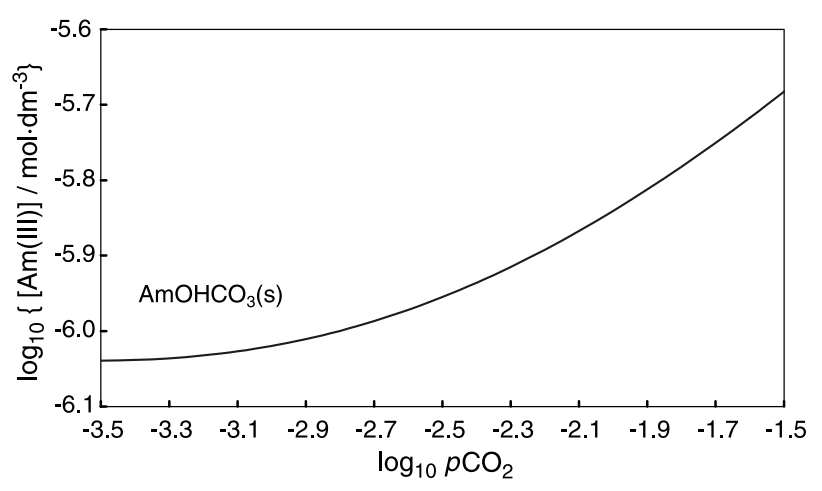

Fig. 4 Americium solubility in bentonite porewater [16]

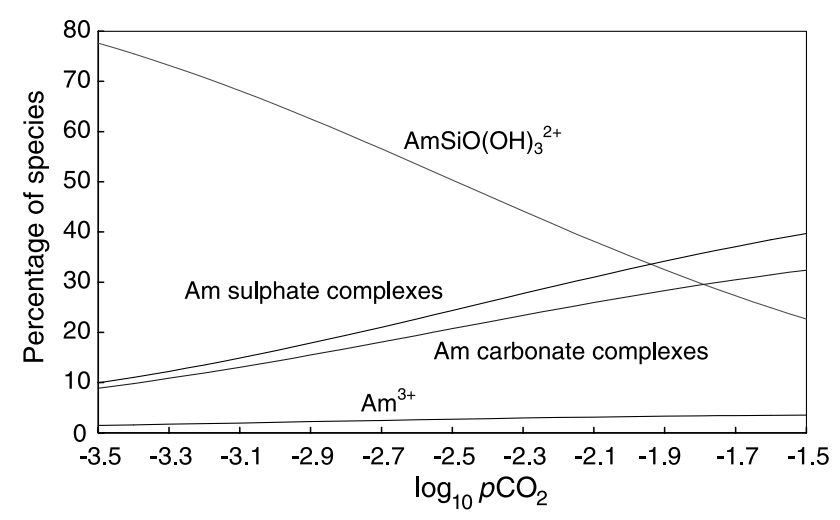

Fig. 5 Americium speciation in bentonite porewater [16]

consequence, the calculated solubility of the solid $\mathrm{AmOHCO}_{3}$ (s) (Fig. 4) and the aqueous speciation of americium (Fig. 5) vary within certain limits as shown in the figures. These uncertainties are considered in subsequent safety calculations [9].

Thermodynamic modeling of solubility limits not only needs parameter ranges of the water chemistry but also a critically reviewed database of chemical thermodynamic constants [17] and careful considerations whether this database is complete with respect to the chemical systems to be modelled [18]. A new feature in the americium example (Fig. 5) is the dominance of an aqueous americium silicate complex in a certain parameter range. Experimental investigations of aqueous silicate complexes of radionuclides commenced a few years ago and are still ongoing.

If chemical thermodynamic constants are too scarce for modeling of a certain system, solubility limits are estimated by scrutinizing experimental evidence related to solubility phenomena or by chemical analogies [16, 19].

Currently, thermodynamic modeling of solubility limits in safety analyses is based on solubility data for pure solid phases. However, most radionuclides are not expected to form pure solid phases but to take part in solid solutions with major host minerals in the repository surroundings. Considering these solid solutions in thermodynamic modeling would result in lower radionuclide concentrations in the aqueous phase.

For example, recent studies of europium forming solid solutions with calcite [20] indicate that the solubility of the chemical analogue americium may not be limited by the pure phase $\mathrm{AmOHCO}_{3}(\mathrm{~s})$ (Fig. 4) but by an americium-calcite solid solution.

Likewise, the solubility of radium may not be determined by the precipitation of pure $\mathrm{RaSO}_{4}(\mathrm{~s})$ but by the formation of a $(\mathrm{Ra}, \mathrm{Ba}) \mathrm{SO}_{4}(\mathrm{~s})$ solid solution [21].

Ongoing research activities aim at obtaining reliable data for safety relevant solid solution systems with the goal of establishing a thermodynamic database for solid solutions.

\section{Sorption}

A further important feature of repository safety is the observation that radionuclides are retarded in their migration through the near field and geosphere of a geological repository by the phenomenon of sorption at the water-rock interface. From a purely phenomenological point of view the experimentally observed distribution of trace amounts of radionuclides between the aqueous phase and a solid phase (defined as the solid/liquid distribution coefficient $R_{\mathrm{d}}=$ $\left(C_{\text {init }}-C_{\text {eq }}\right) / C_{\text {eq }} \cdot V / m$ where $C_{\text {init }}$ is total initial aqueous nuclide concentration $(M), C_{\mathrm{eq}}$ is total equilibrium aqueous nuclide concentration $(M), V$ is volume of liquid phase $\left(\mathrm{dm}^{3}\right)$, and $m$ is mass of solid phase $(\mathrm{kg})$ ) can be interpreted as a sorption process (expressed as a sorption coefficient $K_{\mathrm{d}}$ with the same dimensions as $R_{\mathrm{d}}$ ) if this process is reversible, i.e., if the radionuclides can be desorbed from the solid phase by lowering their concentration in the aqueous phase.

As an example, the americium sorption edges on the clay mineral montmorillonite [22] are shown in Fig. 6. (An americium sorption edge is the solidwater distribution of trace amounts of americium as a function of $\mathrm{pH}$.) The strong effect of ionic strength (i.e., the concentration of the background electrolyte $\mathrm{NaClO}_{4}$ ) on the americium sorption at low $p H$ can be interpreted in terms of an ion ex- 


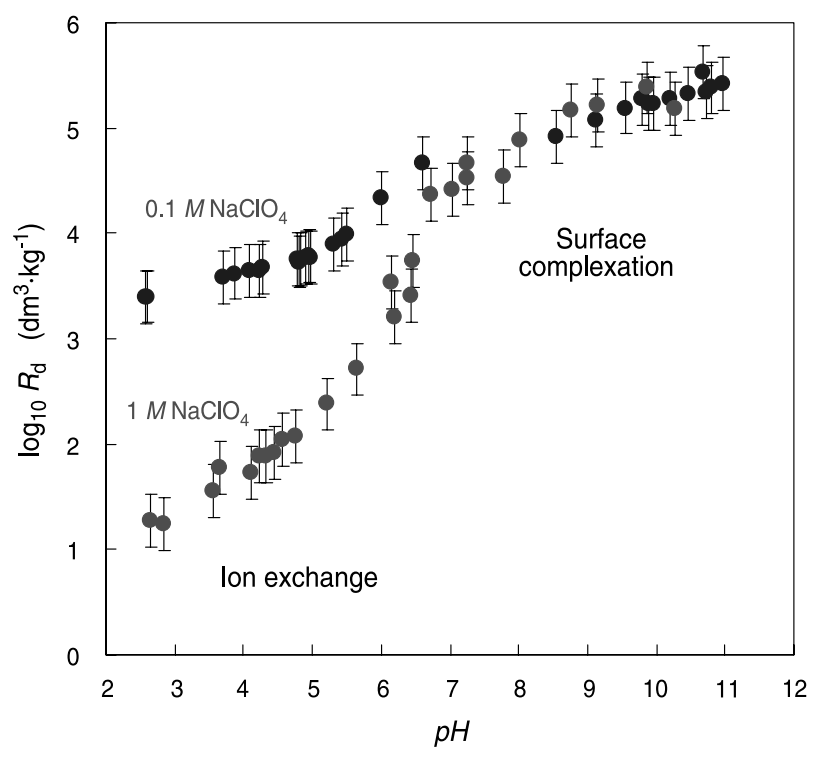

Fig. 6 Americium sorption edges on montmorillonite [22]

change process, whereas sorption in the alkaline $p H$ region could be modelled with the concept of surface complexation.

For Swiss safety analyses sorption databases were prepared at the Paul Scherrer Institut [23-25] either based on batch sorption experiments, as shown in Fig. 6, or based on geochemical sorption models also supported by experimental evidence, or in cases where no reliable experimental data were available, based on chemical analogies [26].

In recent safety analyses radionuclide distributions at the water-rock interface generally were assumed to be reversible, and thus leading to a minimum retardation of radionuclides. The reality, however, might be better represented by a continuum of processes from pure surface phenomena to solid solution formation, which most probably results in a considerably stronger retardation of radionuclides in the geosphere than estimated by current models.

Ongoing research activities aim at a consistent geochemical sorption model for all radionuclides of interest with the goal of establishing a thermodynamic sorption database [27]. A farther reaching goal is a consistent thermodynamic model of the continuum of processes from pure surface phenomena to solid solution formation.

\section{Thermodynamic data: facts and fiction}

Equilibrium thermodynamics is one of the pillars which support safety analyses of repositories for ra- dioactive waste. Thermodynamic constants are used in modeling reference porewaters, calculating radionuclide solubility limits, deriving case specific sorption coefficients, and last but not least in analysing experimental results. It is important to use the same database in all instances of this model chain to guarantee internally consistent results.

\section{$\mathrm{Fe}(\mathrm{III})$ carbonato complexation}

Within the scope of the update of the Nagra thermochemical database $[28,29]$ I reviewed data concerning carbonato complexation of trace metals. The investigation of Bruno et al. [30] attracted my attention because it was at that time the only publication exploring the carbonato complexation of ferric iron, a potentially important product of steel canister corrosion (Fig. 2). Bruno et al. [30] did measurements of dissolved ferric iron for different $\mathrm{CO}_{2}$ pressures at various $p H$ values, starting with $50 \mathrm{~nm}$ spherules of hematite $\left(\mathrm{Fe}_{2} \mathrm{O}_{3}\right)$. My detailed review [31] revealed, besides some inconsistencies in the original data treatment, an unresolved ambiguity in the experiments: a probable surface reaction which transforms hematite into ferrihydrite, " $\mathrm{Fe}(\mathrm{OH})_{3}$ ", during the experiments. Thus, the solubility process investigated by Bruno et al. [30] most probably is not due to hematite dissolution but due to the dissolution of freshly precipitated ferrihydrite.

In their reply Bruno and Duro [32] basically admitted my criticisms, and ultimately my review induced measurements of ferrihydrite solubility in the course of a recently finished $\mathrm{PhD}$ work [33]. The new measurements reveal that there is no obvious difference between hematite and ferrihydrite behavior, and thus confirm my interpretation of surface hydration of hematite into ferrihydrite during solubility experiments. Although the existence of Fe(III) carbonato complexes has been demonstrated, their speciation and formation constants are difficult to get solely from solubility data. Further experimental work using other approaches will be necessary to settle this topic.

\section{Nickel carbonato complexation}

In the framework of the above mentioned data review concerning carbonato complexation of trace metals, and motivated by the need of reliable nickel carbonato complexation data for interpreting experi- 
mental nickel sorption data in carbonate containing solutions, a detailed review of nickel aqueous speciation and solubility at ambient conditions has been carried out [34]. This review revealed that, in contrast to the general opinion, the aqueous speciation of nickel is poorly known, and thus the review has the subtitle "a thermodynamic elegy".

Besides the fairly well established first hydrolysis constant, data are scarce and only poor estimates can be derived for higher Ni hydrolysis constants from a few solubility studies. The situation is even worse in the case of aqueous carbonato complexes. No reliable experimental study had been published at the time of this review and almost all numbers reported in thermodynamic databases are unacceptable estimates. In my review I scrutinised all these published estimates and proposed expectation ranges of nickel carbonato complex stability through correlation with other known thermodynamic constants (as an example, see Fig. 7).

Solubility constants for a few simple nickel solids are known or have been estimated from thermochemical data. However, none of these simple solids is of geochemical relevance at ambient conditions. Based on field evidence, classes of solids are identified which potentially govern nickel concentrations in ground and surface waters. Recent spectroscopic data indicate that magnesium clay minerals and layered double hydroxides are the most prominent candidates for nickel-bearing solids at ambient conditions.

The results of this review triggered an experimental investigation of the nickel carbonate system by an

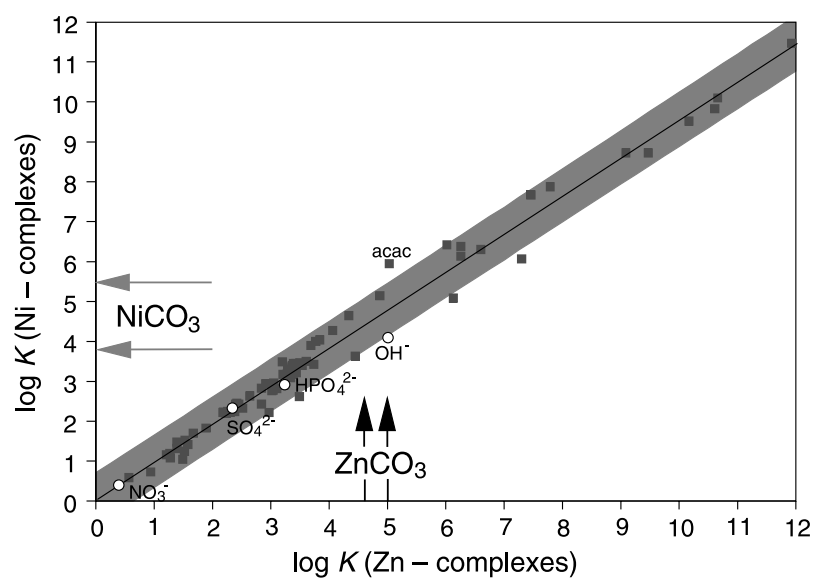

Fig. 7 Zinc-nickel correlation for estimating the complexation constant of $\mathrm{NiCO}_{3}(\mathrm{aq})$. Data at zero ionic strength for mainly small organic and a few inorganic ligands taken from various literature sources [34]

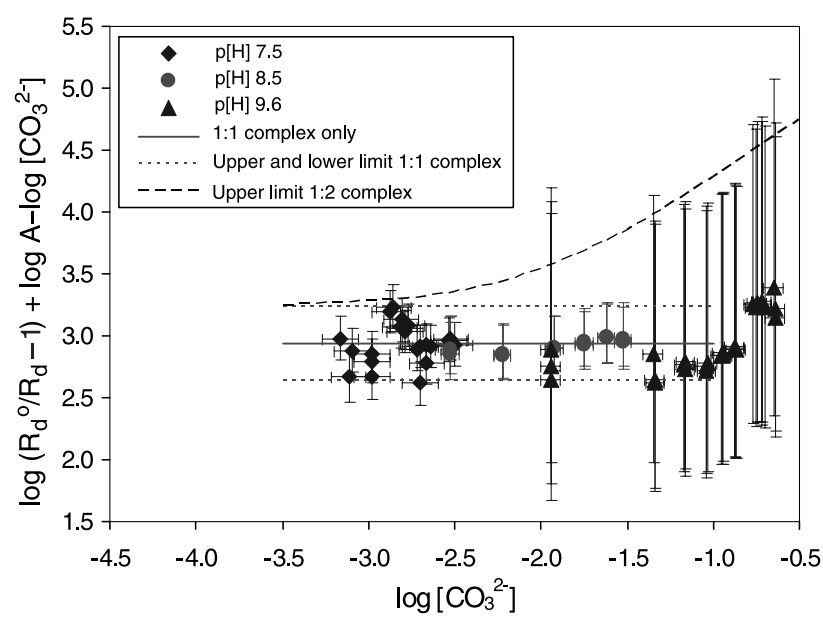

Fig. 8 Summary of nickel carbonate measurements by an ion-exchange method [35]

ion-exchange method [35]. My analysis of the experimental data revealed a general difficulty in the investigation of aqueous metal-carbonate systems: The rather narrow experimental window. At $p H 7.5$ the effect of nickel-carbonato complexation is rather weak and hence, the measured distribution coefficients exhibit a rather large scatter (diamond symbols at $p H 7.5$ in Fig. 8). With increasing $p H$ the carbonato complexation effect becomes stronger and the associated scatter in experimental data becomes smaller (round symbols at $p H 8.5$ in Fig. 8). Above $p H 9$ Ni hydrolysis already plays a potentially important role, and this effect has to be considered as a "side reaction" (term " $\log A$ " in Fig. 8) in data interpretation. However, due to the above mentioned poor estimates for higher Ni hydrolysis constants, the experimental data corrected for these "side reactions" are associated with large uncertainties (triangle symbols at $\mathrm{pH} 9.6$ in Fig. 8). Hence, this work provided the first experimentally determined reliable nickel-carbonato complexation constant but also revealed the current limitations due to missing reliable $\mathrm{Ni}$ hydrolysis constants needed for data interpretation.

The results of these two papers $[34,35]$ constitute the chapter about the aqueous nickel carbonate system in the recently published OECD/NEA TDB review on the chemical thermodynamics of nickel [36].

\section{The Nagra/PSI chemical thermodynamic data base}

The above mentioned topics and many other reviews finally were summarized in the Nagra/PSI chemical 
thermodynamic data base (TDB) 01/01 [17], a project where I had been chairman, coordinator, and one of its five contributors.

The Nagra/PSI TDB is an encyclopedia of thermodynamic data recommended for environmental studies. The database focuses on elements commonly found as major solutes in natural waters, and on actinides and fission products relevant for radioactive waste disposal projects. It is the official chemical thermodynamic database used in Swiss radioactive waste disposal projects. The data included for many elements are based on reviews of the basic literature. The database also includes additional data selected by the authors from recommendations of other experts in groundwater geochemistry and of the international database project (TDB) of the OECD Nuclear Energy Agency (NEA). Data for U, $\mathrm{Np}, \mathrm{Pu}, \mathrm{Am}$, and $\mathrm{Tc}$ recommended by the OECD/ NEA TDB project [37], were considered in the update. Thermodynamic data for Th, Sn, Eu, Pd, Al, and solubility and metal complexation of sulfides and silicates were extensively reviewed.

Our experiences from this two year team effort can be summarized as follows [38]. Detailed inhouse reviews and critical appraisal of NEA recommendations greatly improved the chemical consistency and quality of the selected data. On the other hand, we could discern major gaps in the data, especially missing carbonato complexes. In some systems, e.g., Th(IV) $-\mathrm{H}_{2} \mathrm{O}$ and $\mathrm{U}(\mathrm{IV})-\mathrm{H}_{2} \mathrm{O}$, experimental data could not be described by a unique set of thermodynamic constants. There, a pragmatic approach based on solubility data was chosen for application to performance assessment [39]. The electronic version of our database and information concerning its full documentation is available on our PSI web site (http://www.psi.ch/les).

\section{The OECD/NEA TDB review on selected organic ligands}

In parallel to the above described projects I had been initiator, chairman and one of the five reviewers of the OECD/NEA TDB review on selected organic ligands which commenced in 1998 and lasted for seven years [40]. The review considered not only $\mathrm{U}, \mathrm{Np}, \mathrm{Pu}, \mathrm{Am}, \mathrm{Tc}, \mathrm{Ni}, \mathrm{Se}$, and $\mathrm{Zr}$, but also the major constituents of ground and surface waters, i.e., $\mathrm{H}, \mathrm{Na}$, $\mathrm{K}, \mathrm{Mg}$, and $\mathrm{Ca}$. The decision to evaluate the organic ligands oxalate, citrate, ethylenediaminetetraacetate (edta), and $\alpha$-isosaccharinate (isa) was based on two aspects, namely the importance of the ligands in radioactive waste problems, and the availability of experimental data.

In this review, the scientific literature has been surveyed up to the end of 2004.

Experimental measurements published in journal articles are the main source for the selection of recommended data. When necessary, experimental source data were re-evaluated. Two examples of my experimental data treatment are presented in the following.

\section{Example 1: Oxalate protonation constant}

For the first protonation equilibrium of oxalate,

$$
\mathrm{ox}^{2-}+\mathrm{H}^{+} \rightleftarrows \mathrm{Hox}^{-}
$$

characterized by the equilibrium constant $K_{1}$, I identified 120 experimental measurements as being reliable [40]. The data were obtained from solutions of various concentrations of $\mathrm{LiClO}_{4}, \mathrm{LiNO}_{3}, \mathrm{NaClO}_{4}$, $\mathrm{NaCl}, \mathrm{NaNO}_{3}, \mathrm{KCl}, \mathrm{KNO}_{3}$, and $E t_{4} \mathrm{NI}$ (tetraethylammonium iodide), and were published between 1960 and 2004.

As the selected thermodynamic data in the NEA database refer to standard state conditions, i.e., infinite dilution for aqueous species, all experimental

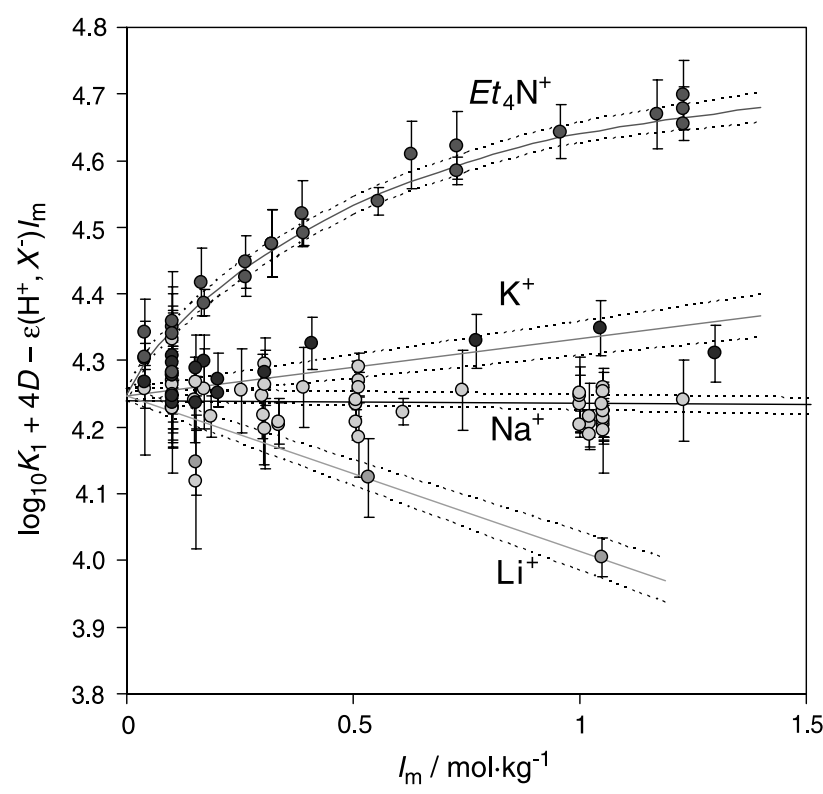

Fig. 9 Constrained least-squares regression plot for the first protonation equilibrium of oxalate [41] 
data have to be extrapolated to zero ionic strength $\left(I_{\mathrm{m}}=0\right)$ as part of the data review procedure.

In the case of oxalate protonation, a constrained least-squares regression procedure has been applied (Fig. 9). This procedure, as described in [40] and executed on a simple spreadsheet, accounts for the fact that a single value of $\log _{10} K_{1}{ }^{\circ}$ (at $I_{\mathrm{m}}=0$ ) should fit all the experimental data, according to the formula

$$
\begin{aligned}
& \log _{10} K_{1}+4 D-\varepsilon\left(\mathrm{H}^{+}, X^{-}\right) \cdot I_{\mathrm{m}} \\
& \quad=\log _{10} K_{1}{ }^{\circ}-\Delta \varepsilon_{1}{ }^{*}\left(M^{+}\right) \cdot I_{\mathrm{m}}
\end{aligned}
$$

Here, $D$ is the Debye-Hückel term, $\varepsilon\left(\mathrm{H}^{+}, X^{-}\right)$are aqueous species interaction constants describing the specific short-range interactions between $\mathrm{H}^{+}$ and $X^{-}$(i.e., $\mathrm{ClO}_{4}{ }^{-}, \mathrm{Cl}^{-}, \mathrm{NO}_{3}{ }^{-}$, or $\mathrm{I}^{-}$), and $\Delta \varepsilon_{1}{ }^{*}$ $\left(M^{+}\right)=\varepsilon\left(\operatorname{Hox}^{-}, M^{+}\right)-\varepsilon\left(\mathrm{ox}^{2-}, M^{+}\right)$are fit parameters, in which $M^{+}$is the cation of the salt solution (i.e., $\mathrm{Li}^{+}, \mathrm{Na}^{+}, \mathrm{K}^{+}$, or $E t_{4} \mathrm{~N}^{+}$). As shown in Fig. 9, all data can be fitted with a common parameter $\log _{10} K_{1}^{\circ}=(4.25 \pm 0.01)$.

\section{Example 2: Calcium oxalate solubility}

A large body of data has been published over the last 100 years concerning the solubility of calcium oxalate hydrates in both pure water and various salt solutions. For the final data analysis, the only studies included in my review were those carried out in $\mathrm{NaCl}$ and $\mathrm{KCl}$ solutions, with proper characterization of the solids in equilibrium with the solutions, and published between 1929 and 1998 [40].

In all cases, the aqueous speciation was recalculated in my review from analytical equilibrium concentration data of dissolved calcium, oxalate, $\mathrm{NaCl}$, or $\mathrm{KCl}$. The results of the speciation calculations, i.e., the calculated concentrations of $\left[\mathrm{Ca}^{2+}\right]$ and $\left[\mathrm{ox}^{2-}\right]$, have been used to determine the solubility product, $K_{\mathrm{s}, 0}$, of the reaction

$$
\mathrm{Ca}(\mathrm{ox}) \cdot \mathrm{H}_{2} \mathrm{O}(\mathrm{cr}) \rightleftarrows \mathrm{Ca}^{2+}+\mathrm{ox}^{2-}+\mathrm{H}_{2} \mathrm{O}
$$

and to extrapolate it to zero ionic strength with the same parameters used in the speciation calculations. The re-evaluated solubility products, $\log _{10} K_{\mathrm{s}, 0}{ }^{\circ}$ valid at zero ionic strength, do not show any systematic variation when plotted against the original solution concentrations (Fig. 10), as expected. This is a strong indication of the internal consistency of the speciation model derived in the NEA TDB review.

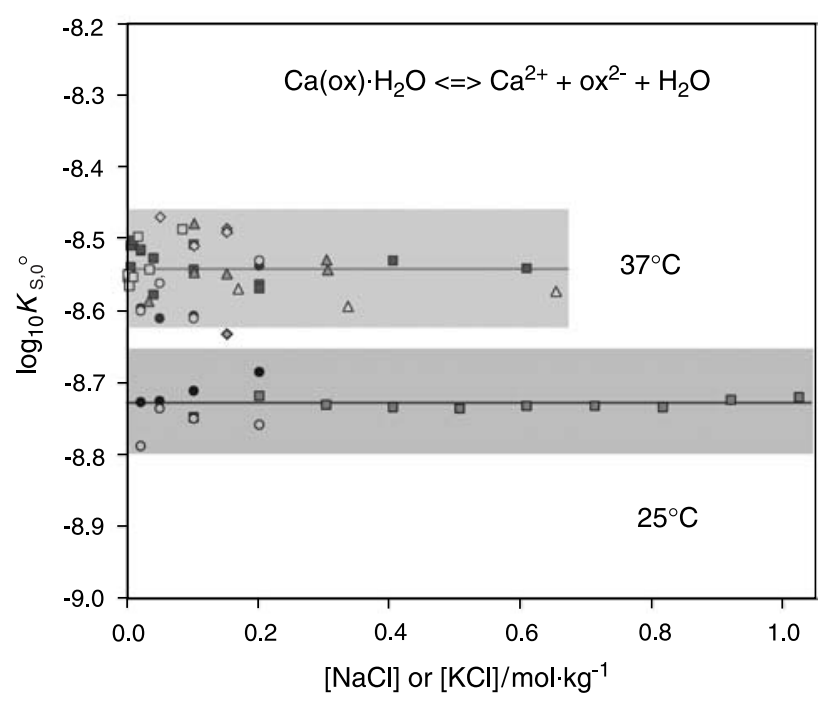

Fig. 10 Solubility products of calcium oxalate mono-hydrate, calculated from analytical solubility data at zero ionic strength, plotted against the original solution concentrations [41]

An overview of the review and more details on data treatment procedures are given in Hummel et al. [41].

Concerning the actinides, reliable values could be selected in the NEA TDB review mainly for $\mathrm{Am}(\mathrm{III}), \mathrm{Np}(\mathrm{V})$, and U(VI) complexes, whereas serious data gaps were found for the tetravalent actinides. Experimental data show that the redox states $\mathrm{U}(\mathrm{III}), \mathrm{U}(\mathrm{V}), \mathrm{Pu}(\mathrm{V}), \mathrm{Am}(\mathrm{V}), \mathrm{Np}(\mathrm{VI}), \mathrm{Pu}(\mathrm{VI})$, and $\mathrm{Am}(\mathrm{VI})$ are unstable in the presence of the selected organic ligands oxalate, citrate and edta [42]. Missing and unreliable thermodynamic data in these unstable redox states are of no importance from the viewpoint of application in environmental modeling studies [42].

\section{Case studies for inorganic and simple organic ligands: the "backdoor approach"}

In many case studies involving inorganic and simple organic ligands a serious lack of reliable thermodynamic data is encountered. There, a new modeling approach to assess the effects of these missing data was applied. This so called "backdoor approach" [43] begins with the question, "What total concentration of a ligand is necessary to significantly influence the speciation, and hence the solubility, of a given trace metal?" 


\section{Degradation products of ion exchange resins}

Low- and intermediate-level radioactive waste contains substantial amounts of ion-exchange resins from decontamination procedures. Degradation of these organic waste forms by radiolysis in a repository is a source of concern in radioactive waste management. It is possible that small, water-soluble, organic ligands may be generated from these waste forms that could strongly coordinate radionuclides resulting in an increase of the solubility of radionuclides and/or a decrease of their sorption on solid phases. These reactions would enhance the release of radionuclides to the geosphere and finally to the biosphere and could increase the dose to man. This concern prompted a series of experimental and modeling studies [44-46].

Radiolytic degradation experiments with strong acidic ion exchange resins resulted in the formation of mainly sulphate and dissolved organic carbon. High-performance liquid chromatography analysis and complexation studies with $\mathrm{Cu}^{2+}$ and $\mathrm{Ni}^{2+}$ showed the presence of two strongly complexing organic ligands: oxalate and ligand $X$. Although ligand $X$ could not be identified, it could be characterised by its concentration, a deprotonation constant, and a complexation constant for the $\mathrm{NiX}$ complex [44].

\section{Complexation of nickel with oxalate and ligand $X$}

In a second step, the influence of these ligands on the $\mathrm{Ni}$ speciation in groundwater and cement porewater of a repository was assessed [45].

First, a complete and reliable thermodynamic database for this case study was built. Missing stability constants have been estimated by chemical reasoning. Subsequent sensitivity analyses showed whether these species are important or not.

In the case of oxalate, the backdoor approach revealed that the oxalate concentration necessary to complex $90 \%{ }^{1} \mathrm{Ni}$ will never be exceeded within the repository or in its environment due to precipitation of Ca-oxalate solids (Fig. 11). Thus, a negative effect of oxalate on $\mathrm{Ni}$ speciation and sorption, i.e., an in-

\footnotetext{
${ }^{1}$ For assessing the influence of Ni-ligand complexation on sorption at some mineral surface, the simplest model assumes that the ligand and its complexes do not sorb at the surface. Then, a 90\% increase in complexation results in a reduction of $\mathrm{Ni}$ sorption by one order of magnitude.
}

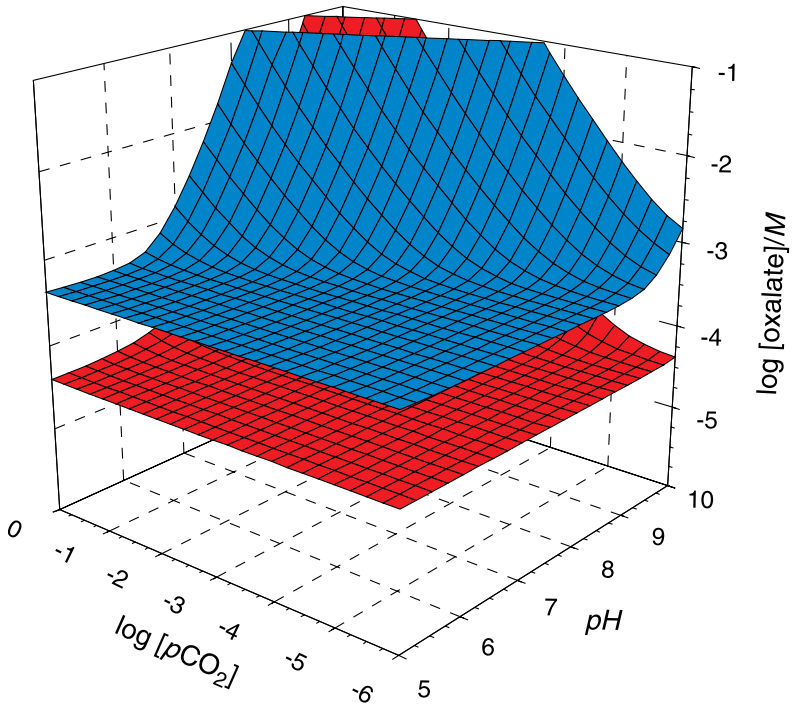

Fig. 11 The influence of oxalate on the complexation of $\mathrm{Ni}$ in groundwater at $[\mathrm{Ca}]=10^{-3} \mathrm{M}$. For any given $\mathrm{pH}$ and $\mathrm{CO}_{2}$ partial pressure the amount of oxalate shown by the blue upper surface is needed to reach $90 \%$ Ni-oxalate complexation. The red lower surface represents the maximum concentration of oxalate which cannot be exceeded in aqueous solution due to the precipitation of Ca-oxalate solids [45]

crease in solubility and a decrease in sorption of $\mathrm{Ni}$, need not to be considered in safety assessments.

In the case of ligand $X$, backdoor calculations demonstrated that $\mathrm{Ni}$ speciation is highly dependent on geochemical conditions (Fig. 12) and is occasionally ambiguous due to uncertainties in estimated stability constants. Hints were given to deal with these ambiguities in future safety assessments, and further experimental investigations were proposed to decrease the uncertainties when necessary [45].

\section{Complexation of $\mathrm{Ni}, \mathrm{Ag}$, and Pd with ammonia}

In a third step, experimental and modeling studies were carried out on the chemical and radiolytic degradation of strong basic anion exchange resins and mixed-bed ion-exchange resins [46].

The most important water-soluble products of the radiolytic degradation of anion exchange resins in a cementitious environment are ammonia and methylamines. These ligands do not form complexes with most radionuclides. Exceptions are $\mathrm{Ni}, \mathrm{Ag}$, and $\mathrm{Pd}$, which form strong complexes with amines.

Other degradation products of anion and mixedbed ion-exchange resins are of no importance concerning the complexation of radionuclides. This is 


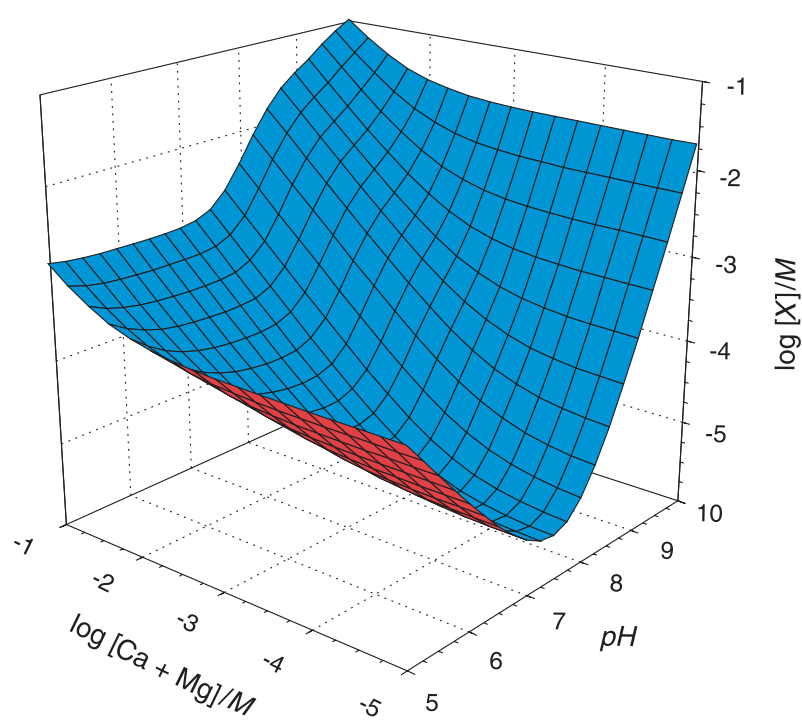

Fig. 12 The influence of ligand $X$ on the complexation of $\mathrm{Ni}$ in groundwater at $p \mathrm{CO}_{2}=10^{-2}$ bars as a function of $p H$ and $[\mathrm{Ca}+\mathrm{Mg}]$ concentration. The maximum values of estimated stability constants were used for the speciation calculations. The 90\% Ni-organic complexation surface is shown [45]

shown indirectly by adsorption experiments: the degradation products do not have a significant effect on the adsorption of Eu(III) on calcite, for example.

The effect of ammonia and methylamines on the complexation of $\mathrm{Ni}, \mathrm{Ag}$, and Pd I investigated by chemical modeling using the backdoor approach (Fig. 13). For $\mathrm{Ni}$ and $\mathrm{Ag}$, rather reliable predictions can be made using available thermodynamic data. In

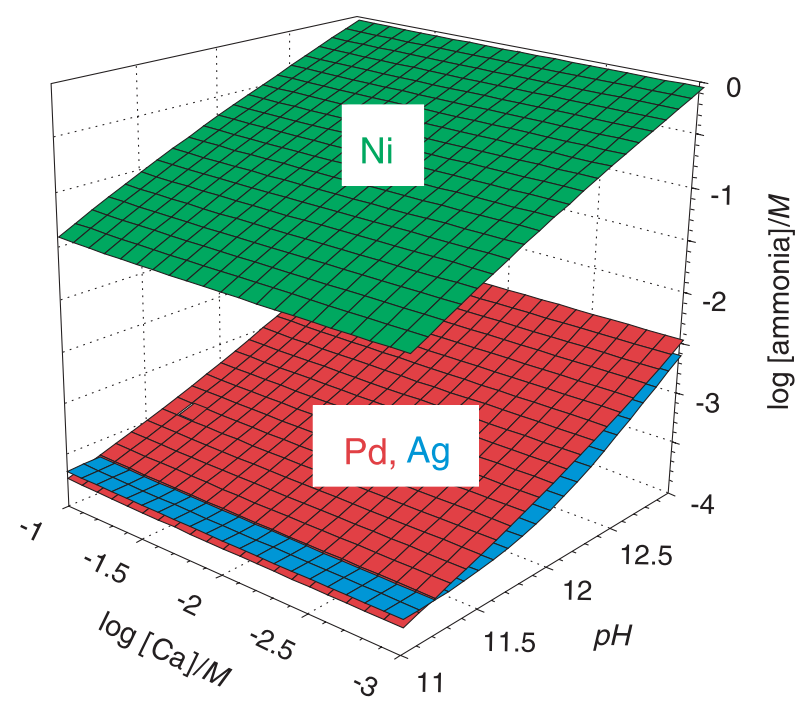

Fig. 13 The influence of ammonia on the complexation of $\mathrm{Ni}, \mathrm{Ag}$, and Pd in high $\mathrm{pH}$ waters. The $50 \%$ metal-ammonia complexation surfaces are shown [46]

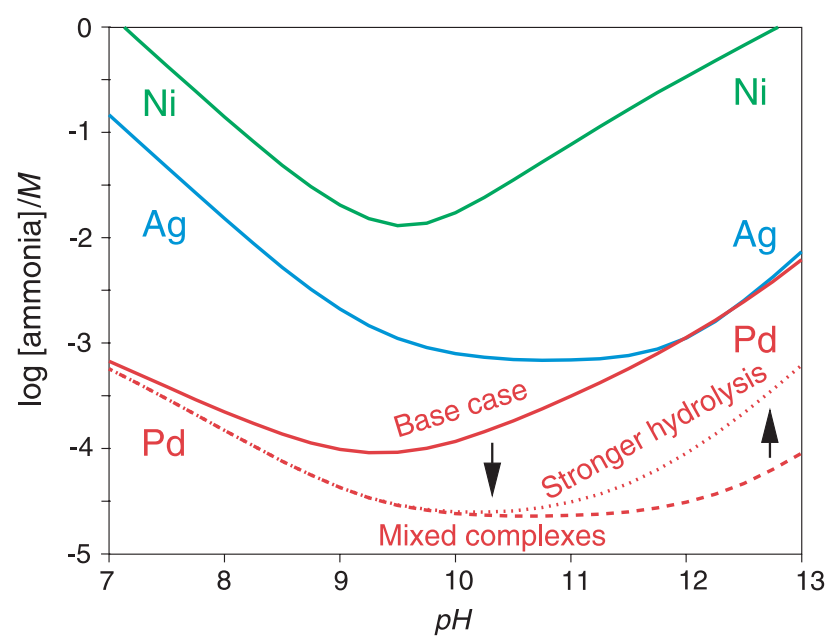

Fig. 14 The concentration of ammonia needed in order to complex $90 \% \mathrm{Ni}, \mathrm{Ag}$, and $\mathrm{Pd}$ in solution. Base case (solid line): stability data as given in the literature. Mixed complexes (dashed line): the formation constants of the mixed complexes are estimated by analogy using aromatic amine hydrolysis data. Stronger hydrolysis (dotted line): the consecutive formation constants of $\mathrm{Pd}(\mathrm{OH})_{3}{ }^{-}$and $\mathrm{Pd}(\mathrm{OH})_{4}{ }^{2-}$ increased by one order of magnitude each [46]

the case of Pd, large uncertainties are encountered due to unreliable data and gaps in the set of important species.

The system Pd(II)-ammonia-water was explored in detail (Fig. 14). Predominant species are inferred by chemical analogy and their thermodynamic data have been estimated. The uncertainty in these estimated values, and the uncertainty in some experimentally determined but ambiguous data, is assessed by qualitative and quantitative chemical reasoning [46].

\section{Prussian Blue and metal cyanide complexation}

Prussian Blue, $\mathrm{Fe}^{\mathrm{III}}{ }_{4}\left[\mathrm{Fe}^{\mathrm{II}}(\mathrm{CN})_{6}\right]_{3}$, and structurally related transition metal compounds are used as caesium ion exchangers in decontamination procedures of liquid radioactive waste. The used ion exchangers are conditioned as cementitious waste form for interim storage and finally will become part of the radioactive waste in geological repositories. The problem discussed by Hummel [47] is the long-term behavior of the ion exchangers $\mathrm{Fe}^{\mathrm{III}}{ }_{4}\left[\mathrm{Fe}^{\mathrm{II}}(\mathrm{CN})_{6}\right]_{3}$ and $\mathrm{Ni}_{2}\left[\mathrm{Fe}(\mathrm{CN})_{6}\right]$ in planned geological repositories.

The worst-case scenario is the instantaneous and complete dissolution and decomposition of the ion exchangers in the cementitious environment and the release of free cyanide. In order to assess the effects 


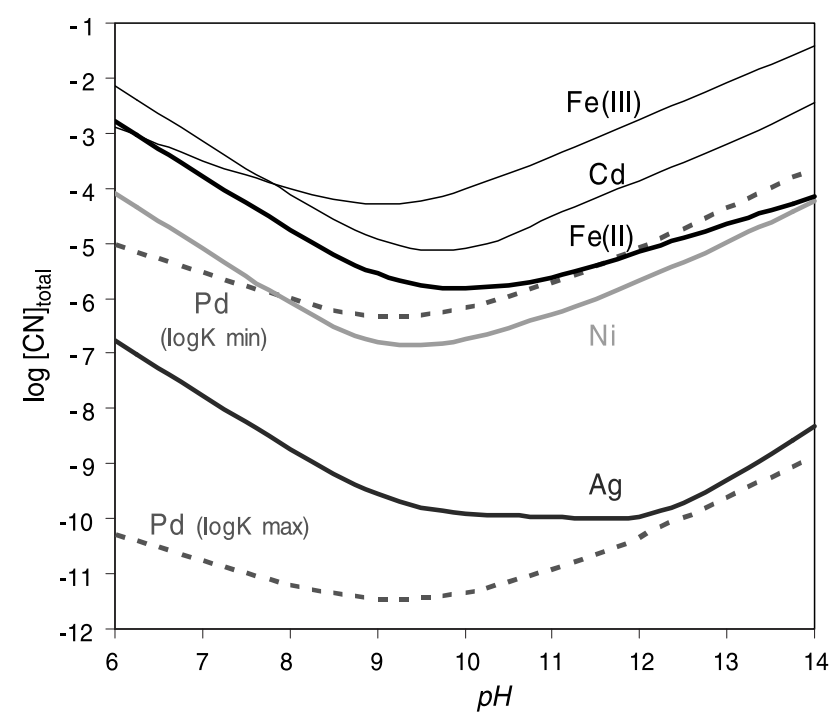

Fig. 15 Concentration of cyanide necessary to complex $90 \%$ of a specified metal. The metal $-\mathrm{H}_{2} \mathrm{O}-\mathrm{NaOH}-\mathrm{HCN}$ system is explored in the range $6 \leq p H \leq 14$ at $I=0$ and $25^{\circ} \mathrm{C}$ [47]

of cyanide complexation on the speciation and solubility of radionuclides first the thermodynamic data necessary for "backdoor" calculations were evaluated in detail, and then the systems metal- $\mathrm{H}_{2} \mathrm{O}-$ $\mathrm{NaOH}-\mathrm{HCN}$ have been explored [47]. The results can be summarised as follows.

All radionuclides belonging to the class of "hard acceptors", e.g., Cs, Sr, Ra, U, Np, Pu, Am, and Cm, are not affected by cyanide complexation under these conditions.

Radionuclides belonging to the class of "soft acceptors" and "borderline" metals, e.g., $\mathrm{Fe}, \mathrm{Co}, \mathrm{Ni}$, $\mathrm{Tc}, \mathrm{Cd}, \mathrm{Pb}, \mathrm{Pd}$, and $\mathrm{Ag}$, are affected to a various degree by cyanide complexation (Fig. 15).

Strong complexation and extensive cyanide leaching I found for $\mathrm{Ni}, \mathrm{Co}, \mathrm{Pd}$, and $\mathrm{Ag}$. In the case of $\mathrm{Co}, \mathrm{Ni}$, and $\mathrm{Ag}$ the dominating complexes are $\mathrm{Co}^{\mathrm{II}}(\mathrm{CN})_{5}{ }^{3-}$ and $\mathrm{Ni}^{\mathrm{II}}(\mathrm{CN})_{4}{ }^{2-}$ (Fig. 16) and $\mathrm{Ag}(\mathrm{CN})_{2}{ }^{-}$, respectively. Pd forms an extremely stable $\mathrm{Pd}(\mathrm{CN})_{4}{ }^{2-}$ complex, but there are large and yet unresolved discrepancies in reported stability constants (Fig. 15).

These results have been considered in further model calculations of a recent performance assessment study for a planned geological repository in Switzerland [9]. They can be used to decide if a cyanide containing waste sort should be separated from other wastes and may also be of value for similar projects elsewhere.

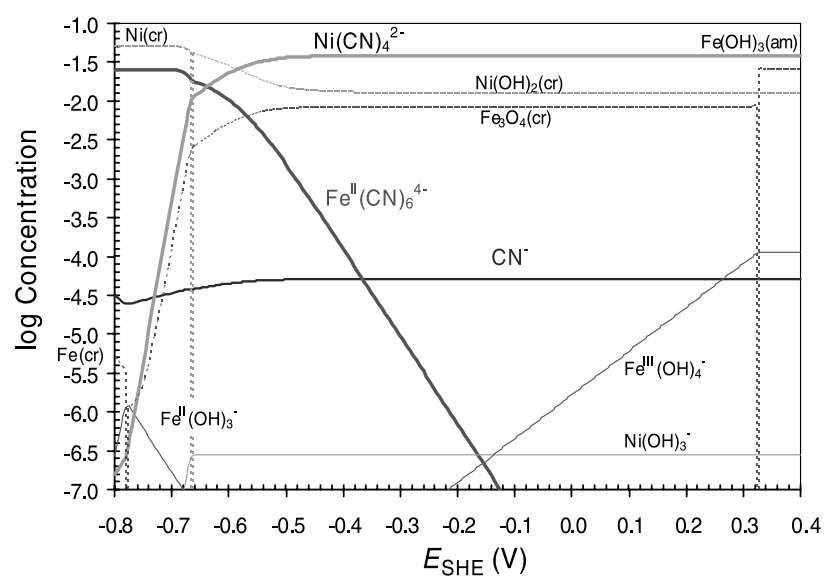

Fig. 16 Calculated species distribution for the $\mathrm{Ni}_{2} \mathrm{Fe}(\mathrm{CN})_{6}-$ $\mathrm{H}_{2} \mathrm{O}-\mathrm{NaOH}-\mathrm{NaCl}$ system in the range $-0.8 \mathrm{~V} \leq E h \leq 0.4 \mathrm{~V}$ (the stability range of $\mathrm{H}_{2} \mathrm{O}$ at $p H 12.5$ ), at $I=0.3 M$ and $25^{\circ} \mathrm{C}, p H=12.5,[\mathrm{NaCl}]=0.16 \mathrm{M}$ and $[\mathrm{CN}]_{\text {total }}=0.15 \mathrm{M}$. Solid lines represent the concentration of dissolved species, whereas dotted lines represent the concentration of precipitated solids, both with respect to the total initial concentration of $\mathrm{Ni}_{2} \mathrm{Fe}(\mathrm{CN})_{6}$ [47]

\section{Solubility and carbonato complexation of tetravalent actinides}

If true thermodynamic equilibrium with a wellknown solid is expected to have been attained, chemical equilibrium thermodynamics allows estimation of the maximum concentration of a given radionuclide in a specified pore fluid of an underground repository. However, in the course of the review process for the Nagra/PSI Chemical Thermodynamic Data Base 01/01 [17] two important cases of insufficient chemical knowledge were identified leading to gaps in the database [39].

First, experimental data for the system $\mathrm{ThO}_{2}-\mathrm{H}_{2} \mathrm{O}$ cannot be interpreted by a unique set of thermodynamic constants. At low $p H$ the solubility of $\mathrm{ThO}_{2}$ strongly depends on the crystallinity of the solid. Differences in solubility of several orders of magnitude have been found between freshly precipitated amorphous and well crystalline solids (Fig. 17). However, with increasing $p H$ the measured concentrations converge, and at neutral and alkaline $p H$ the $\mathrm{ThO}_{2}$ solubility is found to be independent of (bulk) crystallinity (Fig. 17). The solution always seems to "see" the same solid in neutral and alkaline solutions [54]. This behavior is not restricted to Th(IV). Similar patterns have also been found for other tetravalent actinides, An(IV), i.e., U, Np, and $\mathrm{Pu}$ [54]. 


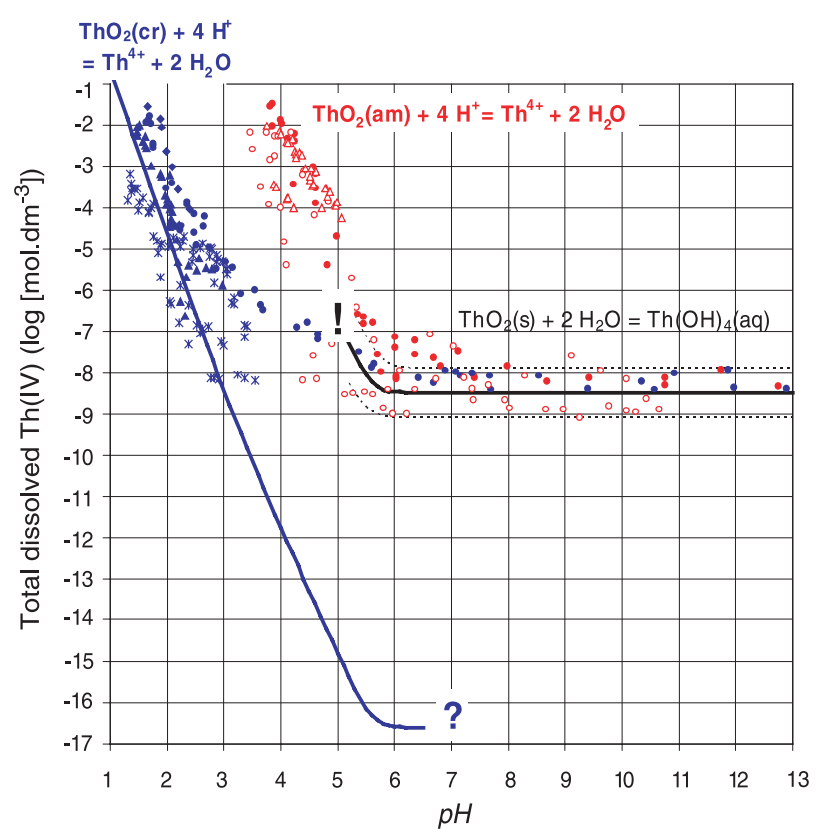

Fig. 17 The enigma of $\mathrm{ThO}_{2}$ solubility: data derived from the solubility of crystalline $\mathrm{ThO}_{2}$ (cr) at low $p H$ cannot describe $\mathrm{ThO}_{2}(\mathrm{~s})$ solubility above $\mathrm{pH} 6$ when using independent $\mathrm{Th}(\mathrm{OH})_{4}(\mathrm{aq})$ formation data (question mark). Vice versa, measured solubilities in alkaline solutions do not point back to the behavior of $\mathrm{ThO}_{2}$ (cr) at acidic conditions (exclamation mark) [39]

Using the "backdoor approach", suited for performance assessment of radioactive waste repositories, we decided to rely on measured solubilities of Th(IV) and U(IV) in neutral and alkaline solutions. Hence, the equilibrium constants selected for the Nagra/PSI TDB [17] do not refer to well defined thorianite, $\mathrm{ThO}_{2}(\mathrm{cr})$, and uraninite, $\mathrm{UO}_{2}(\mathrm{cr})$, used in calorimetric measurements but to the still poorly defined solids $\mathrm{ThO}_{2}(\mathrm{~s})$ and $\mathrm{UO}_{2}(\mathrm{~s})$ encountered in solubility studies. Furthermore, we considered independently determined hydrolysis constants in the case of Th, and adjusted the missing hydrolysis constant of $\mathrm{U}(\mathrm{OH})_{4}(\mathrm{aq})$ in such a way that it is compatible with all experimental solubility measurements in the system $\mathrm{UO}_{2}(\mathrm{~s})-\mathrm{H}_{2} \mathrm{O}-\mathrm{CO}_{2}$ above $\mathrm{pH} 4$ [17]. Consequently, the equilibrium constants in the Nagra/PSI TDB [17] cannot be used to represent the widely varying solubilities of $\mathrm{ThO}_{2}$ and $\mathrm{UO}_{2}$ at low $p H$.

Second, potentially important thermodynamic constants are missing because of insufficient experimental data. Estimations of these missing constants resulted in problem specific database extensions [18].

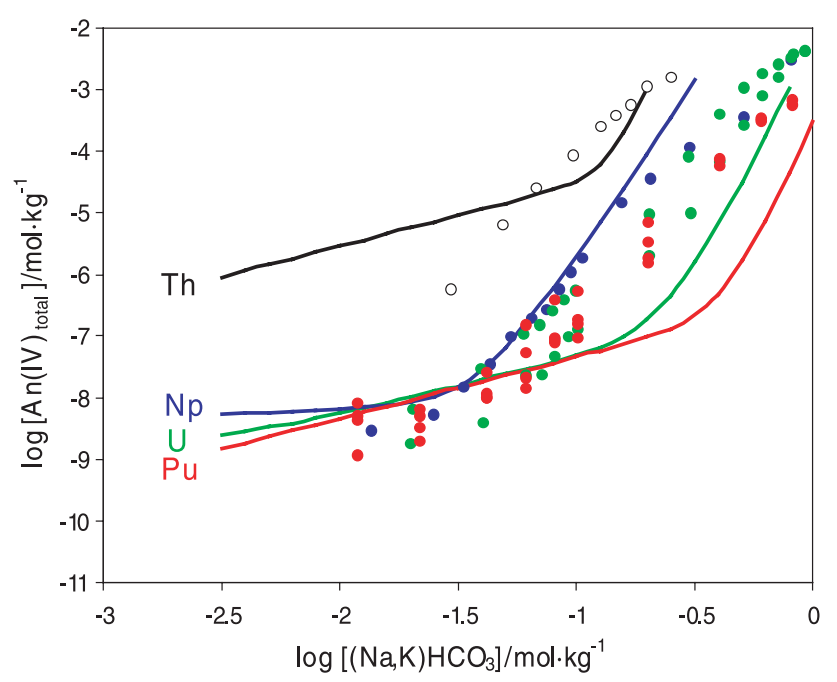

Fig. 18 Experimental solubility data of Th(IV), U(IV), $\mathrm{Np}(\mathrm{IV})$, and $\mathrm{Pu}(\mathrm{IV})$. The solid lines are calculated considering the varying $\mathrm{CO}_{2}$ partial pressure and ionic strength along the $x$-axis using thermodynamic data recommended in the Nagra/PSI TDB 01/01 [17]. In the case of U, Np, and $\mathrm{Pu}$ an additional aqueous species, $\mathrm{AnCO}_{3}(\mathrm{OH})_{3}{ }^{-}$, is included in the speciation model. Its stability constant has been adjusted in all cases to a maximum value still compatible with the experimental data [39]

Especially constants for mixed carbonato-hydroxo complexes of tetravalent actinides I have estimated by the "backdoor approach", i.e., by adjusting constants for $\mathrm{An}^{\mathrm{IV}} \mathrm{CO}_{3}(\mathrm{OH})_{3}{ }^{-}$complexes to maximum feasible values that are still consistent with all available experimental solubility data (Fig. 18) [18, 39]. The estimated constants have no significant effects on the total solubility of $\mathrm{U}, \mathrm{Np}$, and $\mathrm{Pu}$ in the Swiss safety assessment [9]. Introducing new complexes has, however, a remarkable effect on the speciation in solution.

\section{Metal binding by humic compounds: the "conser- vative roof" approach}

The modeling of metal-humate interactions has been a field of active research for more than three decades. Many articles have been published in this time span discussing a multitude of humic binding models. For a review of these binding models see Hummel [48] and Tipping [49].

Summarizing my experience with binding models, I proposed a pragmatic approach for performance assessment purposes, the "conservative roof" approach [50], which does not aim to accurately model all experimental data, but allows estimates of 
maximum effects on metal complexation by humic substances.

In environmental sciences the ultimate goal is to develop most realistic models of a system or of certain effects, e.g., of humic substances on metal speciation. However, in performance assessment it suffices, as an interim step, to estimate the maximum negative influence of the process on the safety of a waste disposal site. In the context of metalhumate interactions we are interested in a conservative estimate of the influence of humic substances on radionuclides.

The meaning of the term "conservative" depends on the scenario (the type of physical/chemical system) being considered. Different scenarios concerning metal-humate interactions can be discerned:

I. If only the mobile fraction of the humic substances is taken into account, and the total metal concentration in the liquid phase is controlled by either the solubility of a solid phase or by sorption on mineral surfaces, an overestimate of the amount bound to humic substances will lead to an overestimate of the amount in the liquid phase, which is conservative.

II. If the total metal content in the liquid phase is limited by the amount available for transport, i.e., if its concentration is not solubility limited and sorption is negligible, the amount of metalhumic binding will not affect the amount of dissolved metals being transported.

III. If only the immobile fraction of the humic substances is considered, and the metal concentration is solubility controlled, metal-humic binding will not influence the amount of metal in solution.

IV. If the metal concentration is not solubility limited and only the immobile fraction of the humic substances is considered, an increase in metalhumic binding will lower the amount available for transport in the liquid phase. An overestimate of the amount of metal-humic binding in this case will not be conservative.

However, the latter scenario is a rather unrealistic one, as in the aqueous phase of a geological repository radionuclide concentrations are generally solubility controlled, and humic substances will at least partly be mobile in the aqueous phase.

The second and third scenario can safely be neglected in performance assessment, as they do not predict any negative influence of metal-humate interactions on the safety of a nuclear waste repository.

Consequently, the following discussion is based on the first scenario, where the term "mobile fraction of the humic substances" has a rather general meaning; it is not distinguished between humic and fulvic acids in true solution and humic colloids transported in the aqueous phase.

\section{A basic definition}

The minimal set of experimental data needed to describe the interaction of a metal ion, $M$, with a humic substance, $H S$, comprises $[M H S]$, the concentration of metal bound to a certain humic substance, $[M]$, the concentration of free metal in the aqueous phase, and $(H S)_{\text {total }}$, the total concentration of humic substance. $[M H S]$ and $[M]$ can be quantified on the molar scale $\left[\mathrm{mol} / \mathrm{dm}^{3}\right]$, but $(H S)_{\text {total }}$ is known only as mass per unit volume $\left(\mathrm{g} / \mathrm{dm}^{3}\right)$.

This minimal set of experimental information can be summarized by a conditional constant ${ }^{c} K$, defined as the number of moles of metal bound per gram of humic substance divided by the concentration of free metal in solution:

$$
{ }^{c} K=\frac{[M H S]}{[M] \cdot(H S)_{\text {total }}}
$$

The unit of ${ }^{c} K$ therefore is volume per mass, usually given as $\mathrm{dm}^{3} / \mathrm{g}$.

In contrast to simple organic ligands with known molecular structure, like oxalate, citrate, or edta, "humic substance" serves just as a label for an operationally defined class of a naturally occurring mixture of medium to large size molecules. Any attempt to calculate the concentration of free humic substance (i.e., the concentration of free binding sites) involves additional model assumptions or additional operational definitions, such as a mean molecular weight, a proton exchange capacity, the degree of proton dissociation, or a loading capacity. These different assumptions and definitions invariably lead to different values for the concentration of free binding sites and thus result in different values for complexation constants. Hence, as discussed in detail by Hummel [48], the concentration of free binding sites is a model dependent parameter. In order to avoid ambiguities due to this model dependent parameter, for the following intercompari- 


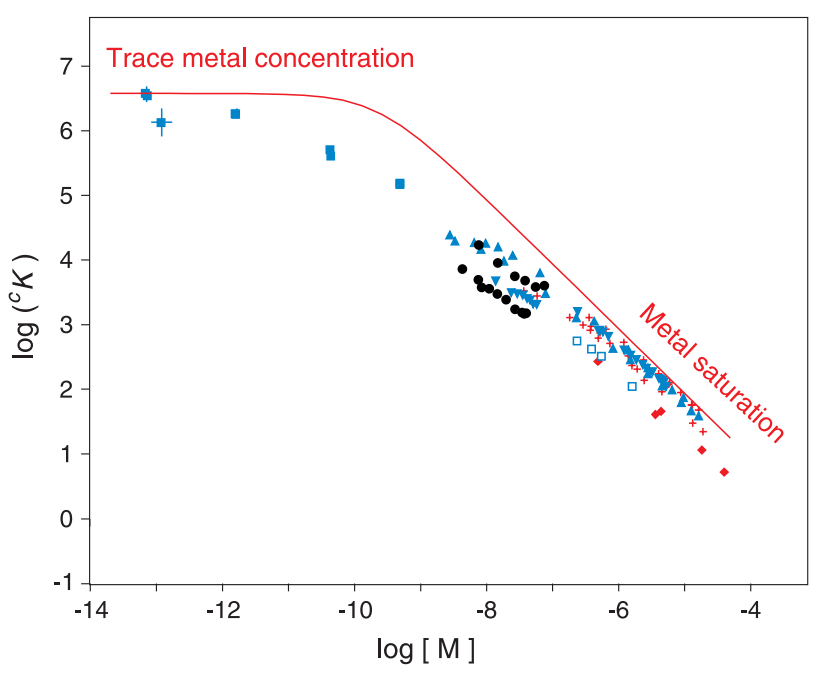

Fig. 19 The metal concentration effect of $\mathrm{Eu}(\mathrm{III})$ (blue), Am(III) (red), and $\mathrm{Cm}$ (III) (black)-humate interactions at pH 4.5-5.5 and ionic strength $0.1 M$ for various humic and fulvic acids. The solid line on top of the data represents the trace of the "conservative roof" approach [50]

sons all experimental data were re-evaluated and given as $\log _{10}{ }^{c} K$ values.

\section{The metal concentration effect}

A synopsis of experimental data for the trivalent cations $\mathrm{Eu}, \mathrm{Am}$, and $\mathrm{Cm}$ from different laboratories, measured with different methods and comprising different humic substances, reveals a very consistent pattern of the metal concentration effect (Fig. 19): with decreasing radionuclide concentration (and all other parameters held constant) an increase in the complexation of the radionuclides with humic substance is observed [51].

However, it is not feasible to represent in detail the entire range of data by assuming just a single complexation site for metal-humate interactions. More than one kind of ligand site has to be considered, and multiple site models or continuous distribution models have to be used for a precise description of the pattern shown in Fig. 19 [48].

The observation of a consistent pattern of experimental data that is difficult to model is not surprising if we consider "humic substance" as a mixture of molecules or as large structures containing different binding sites. Some binding sites of these molecules or structures are expected to exhibit stronger affinity to metal ions than others. These strong binding sites determine the metal uptake at very low metal con- centrations. With increasing metal concentration the strong sites reach saturation and weaker binding sites determine the metal uptake resulting in an overall decrease of metal-humate interaction with increasing metal concentration. Actually, a debate whether "strong" and "weak" binding sites are real or just artefacts of inappropriate experimental procedures triggered my investigation of the metal concentration effect [51].

From the viewpoint of performance assessment, a simple treatment of the metal concentration effect in terms of a single site model is sufficient as a first step. The solid line in Fig. 19 represents the trace of the "conservative roof" approach [50] using a single site model. The "conservative roof" has been adjusted to experimental data in such a way that the maximum effects of metal-humate interactions are bound at trace metal concentration and in the metal saturation range. In the intermediate range of metal concentration the "conservative roof" overestimates the metalhumate interactions by about one order of magnitude.

\section{The effect of $\mathrm{pH}$}

At trace metal concentrations, the concentration range of radionuclides relevant for performance assessment, the variation of experimental ${ }^{c} K$ values with $p H$ is a general observation made in investigations of metal-humate interactions. A synopsis of experimental results for the interactions of humic

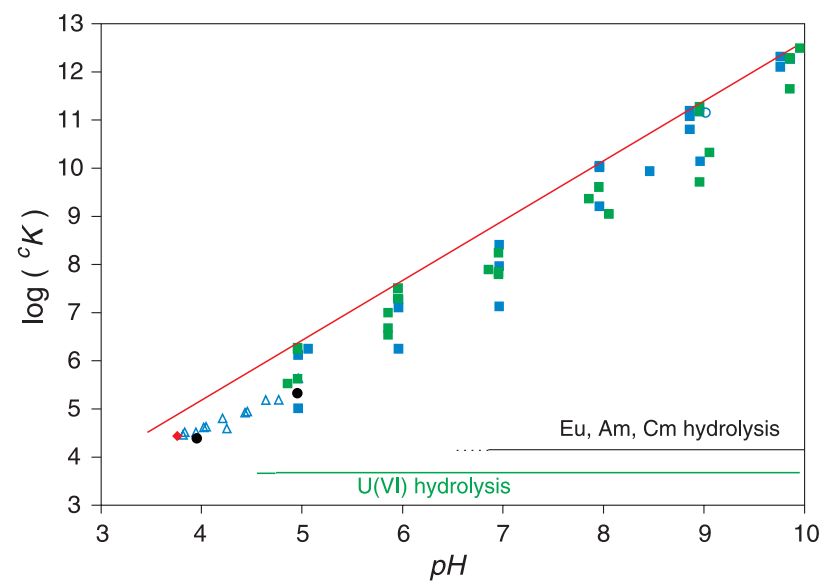

Fig. $20 p H$ dependence of U(VI) (green), Eu(III) (blue), Am(III) (red), and Cm(III) (black)-humate interactions at trace metal concentration. The solid line on top of the data represents the trace of the "conservative roof" approach [50]. The $p H$ ranges of $\mathrm{U}(\mathrm{VI})$ hydrolysis and $\mathrm{Eu}, \mathrm{Am}$, and $\mathrm{Cm}$ hydrolysis are shown as horizontal lines 
substances with $\mathrm{U}(\mathrm{VI}), \mathrm{Eu}(\mathrm{III}), \mathrm{Am}(\mathrm{III})$, and $\mathrm{Cm}(\mathrm{III})$ at trace concentrations may serve as an illustration (Fig. 20): data measured by different authors using humic and fulvic acids from various sources within the $p H$ range $3.8-10$ at an ionic strength $0.1 \mathrm{M}$ exhibit a very strong $p H$ dependence, even in the acidic $p H$ range.

The observation that $\log _{10}{ }^{c} K$ increases with $p H$ with a slope close to one seems to corroborate the assumption of a simple metal-proton exchange reaction, where one metal ion replaces one proton at a humic binding site. However, the slope in Fig. 20 is $1.25 \pm 0.06$, which cannot be described by a simple $1: 1$ (or 1:2) metal-proton exchange reaction.

An alternative interpretation of Fig. 20 may assume the formation of ternary complexes with hydroxide ions, i.e., the formation of $M(O H)_{n} H S$ complexes, where $n=1$ and 2. However, the different hydrolysis behavior of $\mathrm{U}(\mathrm{VI})$ and $\mathrm{Eu}(\mathrm{III})$ should somehow be reflected in the variation of $\log _{10}{ }^{c} K$ with $p H$. Furthermore, the formation of ternary hydroxide complexes is not expected to result in a linear behavior as shown in Fig. 20.

In summary, the apparently simple linear $\log _{10}{ }^{c} K$ $-p H$ behavior does not lead to a simple model in terms of reaction mechanisms. However, whatever model is used to describe the $p H$ effect of metalhumate interactions, for performance assessment it should reflect the maximum effect revealed by experimental data, i.e., it should result in a function close to the straight line shown in Fig. 20. Actually,

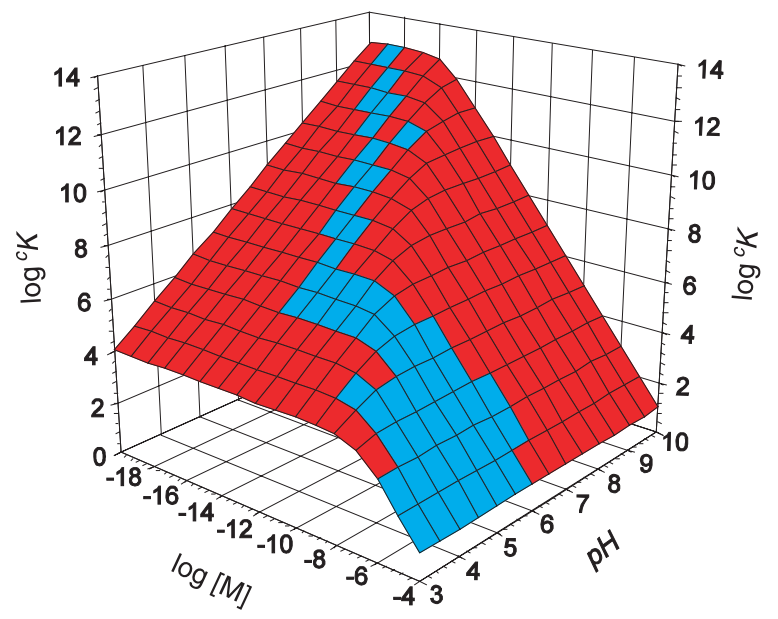

Experimental data available

Fig. 21 Three-dimensional view of the "conservative roof" approach for $\mathrm{Eu}[50]$ the straight line represents the trace of the "conservative roof" approach.

A three-dimensional view of the "conservative roof" approach for Eu(III), summarizing the $p H$ and metal concentration effects, is shown in Fig. 21 [50].

\section{Competition effects}

The interaction of metal ions with humic substances is treated in most binding models within the framework of equilibrium thermodynamics. Therefore, in principle, all other equilibria in the chemical system are expected to influence these interactions. From the viewpoint of performance assessment it is enough to demonstrate that a certain class of competition reactions may decrease radionuclidehumate interactions in all cases, independent of the binding model. A conservative binding model may then safely ignore this class of competition, if not enough experimental data are available to include the effects in a proper way into the model.

\section{Competition of other metal ions with radionuclides}

The most obvious competitive effect is the competition of radionuclides with other metal ions like $\mathrm{Ca}^{2+}$, $\mathrm{Mg}^{2+}, \mathrm{Fe}^{2+}$, and $\mathrm{Al}^{3+}$. These metal ions are major constituents of common groundwaters and they are known to form rather stable aqueous complexes with small organic molecules. Therefore, they have also to be considered as effective competitors for the binding sites of humic substances.

The theoretical predictions of competitive effects of metal ions with radionuclides range from very strong to zero. More precise predictions can be achieved by considering chemical systematics, especially linear free energy relationships, as described in some detail by Hummel [48].

However, in any case, competing metal ions may only decrease the influence of humic substances on radionuclide complexation and can be neglected for conservative estimates in performance assessment.

\section{Competition of other anions with humic binding sites}

In contrast to competition by metal ions, competition by anions like $\mathrm{CO}_{3}{ }^{2-}, \mathrm{OH}^{-}, \mathrm{F}^{-}, \mathrm{SO}_{4}{ }^{2-}$, or $\mathrm{PO}_{4}{ }^{3-}$ takes place in an indirect way. The model dependence of this effect is also less obvious than in the case of metal ions. 
If metal ions are assumed to form only binary complexes with humic substances, competing anions may only decrease the influence of humic substances on radionuclide complexation. However, completely neglecting anion competition would result in over-conservative estimates. At least, hydrolysis and carbonato complexation of radionuclides should be included in conservative estimates.

If formation of mixed or ternary complexes in addition to binary complexes is assumed, the predicted influence of anion competition becomes more complicated. The formation of ternary complexes can be envisioned either as the uptake of metal-anion aqueous complexes by humic substances, or as the binding of anions to metal ions which are already bound by humic substances. The influence of ternary complexes is shown in Fig. 22 as bent lines.

In contrast to binary anion competition, ignoring ternary complexes may lead to significant underestimation of radionuclide-humate interactions. Experimental data indicate $[52,53]$ that the formation of a ternary metal-humate-ligand complex, $M(H S) L$, is always weaker than the formation of a 1:2 metal-

Radionuclides, e.g., $\mathrm{NpO}_{2}^{+}, \mathrm{UO}_{2}^{2+}, \mathrm{Am}^{3+}, \mathrm{Th}^{4+}$

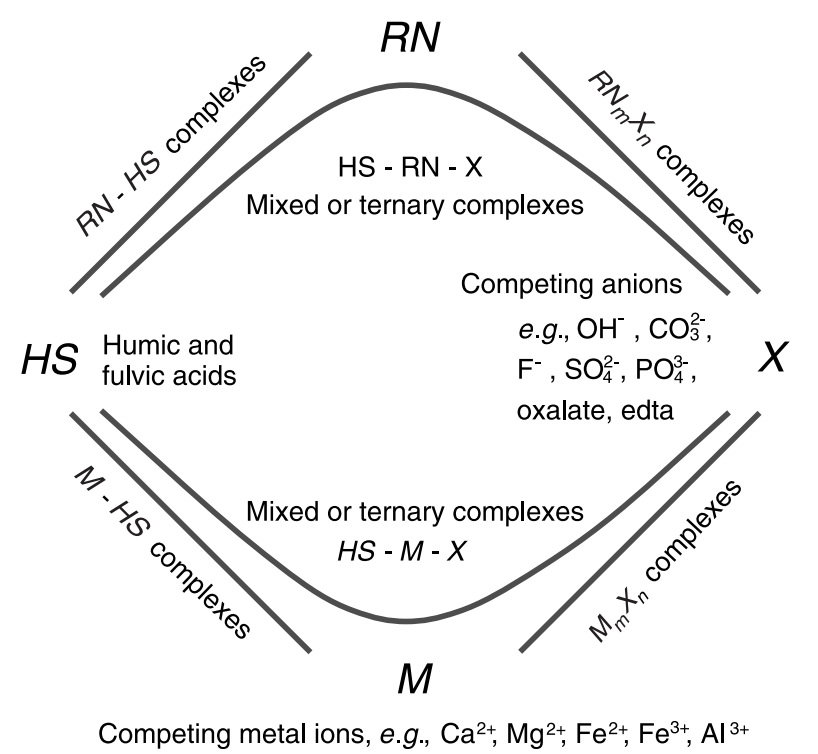

Fig. 22 Schematic representation of competitive effects in radionuclide-humate interactions. The closed circle shows competition of other anions with humic binding sites, combined with metal ion competition. The influence of ternary complexes is shown as bent lines, connecting humics, radionuclides, and anions, and connecting humics, competing metal ions, and anions [48] ligand complex, $M L_{2}$. Therefore, the stepwise stability constant $K_{2}$ of the reaction $M L+L \rightleftarrows M L_{2}$ can be used as a conservative upper limit for the reaction $M(H S)+L \rightleftarrows M(H S) L$. For estimates concerning natural groundwaters, in a first step only ternary complexes involving carbonate need to be considered in performance assessment. The $p H$ effect discussed above implicitly includes possible formation of ternary complexes with hydroxide ions. Other anions are either too weak (like $\mathrm{SO}_{4}{ }^{2-}$ ) or in general too low in concentration (like $\mathrm{F}^{-}$) to form significant amounts of ternary complexes.

\section{Competition of mineral surface sites with humic binding sites}

Interactions of radionuclides with surface sites, summarized as sorption phenomena, are important mechanisms of radionuclide retention in the geologic environment of a repository (Fig. 2). From the viewpoint of performance assessment, competition of surface sites with binding sites of humic substances therefore are discussed in terms of reducing radionuclide sorption by complexation with humic substances. In order to emphasize the importance of surface phenomena, the mineral surface sites are

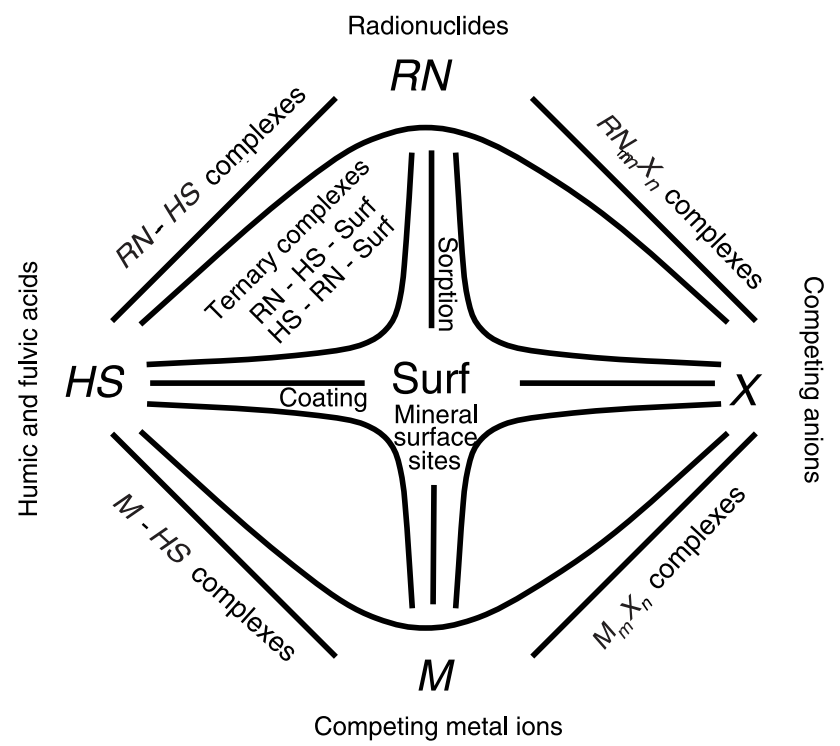

Fig. 23 Complete sketch of mutual interactions of radionuclides, humic substances, competing metal ions, and anions, and mineral surface sites. Straight lines indicate binary interactions, whereas bent lines show ternary complex formation [48] 
placed in the very centre of the sketch of metal ion interactions (Fig. 23).

If interactions of humic substances $(H S)$ with mineral surface sites (Surf) are neglected, then "pure inorganic" sorption remains as competitive effect (Fig. 23). The competing equilibria $R N-H S$ and $R N$-Surf are shifted towards $R N$-Surf by increasing the strength of surface interactions and/or increasing area of active mineral surfaces. This type of indirect competition is very similar to the competing effects of anions if only binary complexes are considered. Hence, assuming that all humic substance is in the aqueous phase, competition of humic binding sites with surface sites always reduces radionuclide sorption by complexation with humic substances. Speciation calculations based on this scenario and using the "conservative roof" approach [50] result in "sorption reduction factors" used in performance assessment.

If humic substance sorbs at surface sites, it may form an organic coating. This coating may significantly alter the sorption capacity of the immobile phase because it is expected to interact with radionuclides in the same way as humic substances in solution, but now forming immobile ternary complexes of the type $R N-H S-$ Surf (Fig. 23). In addition, a second type of ternary complexes, $H S_{-}$ $R N-$ Surf, may be formed (Fig. 23), where the humic substance is "glued" to mineral surfaces via metal ions forming bridges between humic binding sites and surface sites. This type of ternary complexes can be envisioned as sandwich structures. The net effect of organic coating and formation of immobile ternary complexes on sorption of radionuclides is hard to predict. It depends on the ratio of complexation strengths of radionuclides with organic binding sites and surface sites, and is in addition expected to show strong $\mathrm{pH}$ dependence. If both, the humic acid and the mineral surface are negatively charged, little interaction is expected due to strong electrostatic repulsion. Strong interaction may only occur within a $p H$ region where the mineral surface is positively charged and the humic acid still is sufficiently deprotonated. Competing metal ions and anions further complicate the picture, as shown in Fig. 23.

\section{Summary and conclusions}

The $p H$ and metal concentration effects are included in the "conservative roof" approach in a simplified

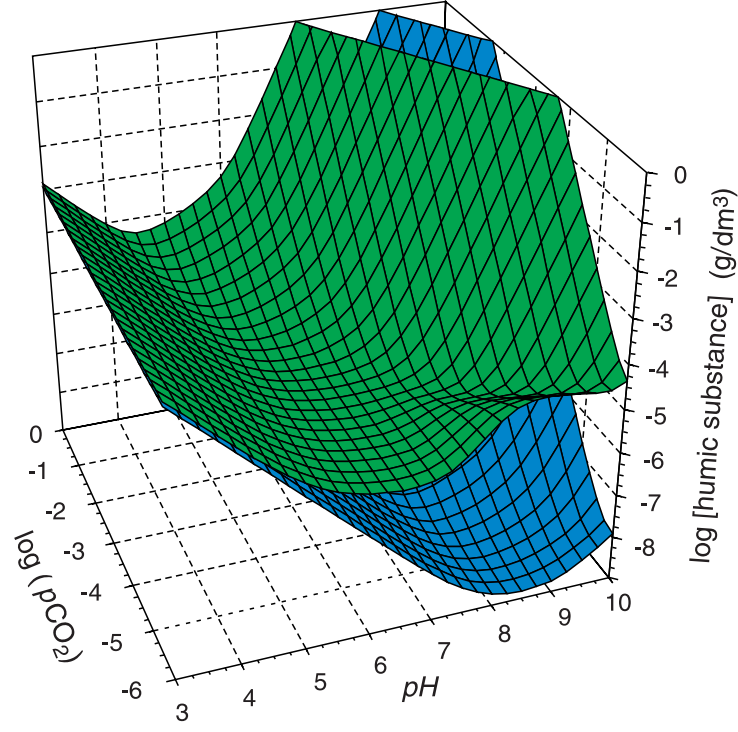

Fig. 24 Three-dimensional representation of the conditions $\left(p H, p \mathrm{CO}_{2}\right.$, and $\left.(H S)_{\text {tot }}\right)$, at which $90 \%$ of the total concentration of $\mathrm{U}(\mathrm{VI})$ (green upper surface) and $\mathrm{Eu}(\mathrm{III})$ (blue lower surface) is bound to humic substance [50]

form suitable for performance assessment. The competition effects were explored by the "backdoor approach" using the "conservative roof" model and additional thermodynamic information [50].

A worked case study for performance assessment of a Swiss geological repository project elucidates all important effects in quantitative terms (e.g., Fig. 24). This case study may serve as a roadmap for the design of more sophisticated approaches to deal with radionuclide-humate interactions in future performance assessments.

\section{Acknowledgement}

Partial financial support by the Swiss National Cooperative for the Disposal of Radioactive Waste (Nagra) is gratefully acknowledged.

\section{References}

1. Hummel W (2006) Radioactive Contaminants in the Subsurface: The Influence of Complexing Ligands on Trace Metal Speciation. Habilitation Thesis, ETH Zurich, Zurich, Switzerland

2. Hummel W, Schneider JW (2005) Chimia 59:909

3. Witherspoon PA, Bodvarsson GS (2006) Geological Challenges in Radioactive Waste Isolation: Fourth Worldwide Review. LBNL-59808, Ernest Orlando Lawrence Berkeley National Laboratory, Berkeley, USA 
4. ONDRAF (2001) Technical Overview of the SAFIR 2 Report: Safety assessment and feasibility interim report 2. NIROND-2001-05E. ONDRAF, Brussels, Belgium

5. Vieno T, Nordman H (1999) Safety assessment of spent fuel disposal in Hästholmen, Kivetty, Olkiluoto and Romuvaara: TILA-99. Posiva Report 99-07. Posiva Oy, Helsinki, Finland

6. ANDRA (2001) Dossier 2001 Argile sur l'avancement des études et recherches relatives à la faisabilité d'un stockage de déchets à haute activité et à vie longue en formation géologique profonde: Rapport de synthèse. ANDRA, Châtenay-Malabry, France

7. JNC (2000) H12: Project to Establish the Scientific and Technical Basis for HLW Disposal in Japan: Second Progress Report on Research and Development for the Geological Disposal of HLW in Japan. JNC TN1410 2000-001. JNC, Tokyo, Japan

8. SKB (1999) Deep Repository for Spent Nuclear Fuel: SR 97: Post-closure Safety: Main Report. Technical Report TR-99-06. SKB, Stockholm, Sweden

9. Nagra (2002) Project Opalinus Clay: Safety Report. Demonstration of Disposal Feasibility for Spent Fuel, Vitrified High-level Waste and Long-lived Intermediatelevel Waste (Entsorgungsnachweis). Nagra Technical Report NTB 02-05. Nagra, Wettingen, Switzerland

10. McNeisch JA (2000) Total System Performance Assessment for the Site Recommendation: Yucca Mountain Project. TDR-WIS-PA-000001 REV 00 ICN 01. U.S. Department of Energy, Yucca Mountain Project, USA (CD)

11. Curti E (2003) Glass Dissolution Parameters: Update for "Entsorgungsnachweis". Nagra Technical Report NTB 02-21 and PSI Bericht Nr. 03-18, Paul Scherrer Institut, Villigen, Switzerland

12. Bradbury MH, Baeyens B (2003) J Cont Hydr 61:329

13. Curti E, Wersin P (2002) Assessment of Porewater Chemistry in the Bentonite Backfill for the Swiss SF/ HLW Repository. Nagra Technical Report NTB 02-09, Nagra, Wettingen, Switzerland

14. Pearson FJ (2002) Benken Reference Water Chemistry. Unpubl. Nagra Internal Report, Nagra, Wettingen, Switzerland

15. Hummel W (2007) Solubility of Solids in Radioactive Waste Repositories. In: Letcher TM (ed) Developments and Applications in Solubility. The Royal Society of Chemistry, Cambridge, UK, $323 \mathrm{p}$

16. Berner U (2002) Project Opalinus Clay: Radionuclide Concentration Limits in the Near Field of a Repository for Spent Fuel and Vitrified High-level Waste. Nagra Technical Report NTB 02-10 and PSI Bericht Nr. 0222, Paul Scherrer Institut, Villigen, Switzerland

17. Hummel W, Berner U, Curti E, Pearson FJ, Thoenen T (2002) Nagra/PSI Chemical Thermodynamic Database 01/01. Nagra Technical Report NTB 02-16 and Universal Publishers, Boca Raton, Florida, USA

18. Hummel W, Berner U (2002) Application of the Nagra/ PSI TDB 01/01: Solubility of Th, U, Np, and Pu. Nagra Technical Report NTB 02-12, Nagra, Wettingen, Switzerland
19. Berner U (2003) Project Opalinus Clay: Radionuclide Concentration Limits in the Near Field of a Repository for Long-lived Intermediate-level Waste. Nagra Technical Report NTB 02-22 and PSI Bericht Nr. 02-26, Paul Scherrer Institut, Villigen, Switzerland

20. Curti E, Kulik D, Tits J (2005) Geochim Cosmochim Ac 69:1721

21. Berner U, Curti E (2002) Radium Solubilities from SF/HLW Wastes Using Solid Solution and Co-precipitation Models. PSI Technical Report TM-44-02-04, Paul Scherrer Institut, Villigen, Switzerland

22. Gorgeon L (1994) Contribution à la modélisation physico-chimique de la retention de radioélements à vie longue par des matériaux argileux. $\mathrm{PhD}$ Thesis, Université Paris 6, Paris, France

23. Bradbury MH, Baeyens B (2003) Near Field Sorption Data Bases for Compacted MX-80 Bentonite for Performance Assessment of a High Level Radioactive Waste Repository in Opalinus Clay Host Rock. Nagra Technical Report NTB 02-18 and PSI Bericht Nr. 03-07, Paul Scherrer Institut, Villigen, Switzerland

24. Bradbury MH, Baeyens B (2003) Far Field Sorption Data Base for Performance Assessment of a High Level Radioactive Waste Repository in an Undisturbed Opalinus Clay Host Rock. Nagra Technical Report NTB 0219 and PSI Bericht Nr. 03-08, Paul Scherrer Institut, Villigen, Switzerland

25. Wieland E, Van Loon LR (2003) Cementitious Near Field Sorption Data Base for Performance Assessment of an ILW Repository in Opalinus Clay. Nagra Technical Report NTB 02-20 and PSI Bericht Nr. 03-06, Paul Scherrer Institut, Villigen, Switzerland

26. Wersin P, Schwyn B (2004) Project Opalinus Clay: Integrated Approach for the Development of Geochemical Databases Used for Safety Assessment. Nagra Technical Report NTB 03-06, Nagra, Wettingen, Switzerland

27. Bradbury MH, Baeyens B (2005) Geochim Cosmochim Ac 69:875

28. Pearson FJ, Berner U (1991) Nagra Thermochemical Data Base I. Core Data. Nagra Technical Report NTB 91-17, Nagra, Wettingen, Switzerland

29. Pearson FJ, Berner U, Hummel W (1992) Nagra Thermochemical Data Base II. Supplemental Data. Nagra Technical Report NTB 91-18, Nagra, Wettingen, Switzerland

30. Bruno J, Stumm W, Wersin P, Brandberg F (1992) Geochim Cosmochim Ac 56:1139

31. Hummel W (2000) Geochim Cosmochim Ac 64:2167

32. Bruno J, Duro L (2000) Geochim Cosmochim Ac 64:2173

33. Grivé I Solé M (2005) The Linkage Between Uranium, Iron, and Carbon Cycling Processes at Interfaces: Evidences from Combined Solution Chemical and Spectroscopic Studies. PhD Thesis, Universitat Politècnica de Catalunya, Barcelona, Spain

34. Hummel W, Curti E (2003) Monatsh Chemie/Chem Monthly 134:941

35. Baeyens B, Bradbury MH, Hummel W (2003) J Solution Chem 32:319 
36. Gamsjäger H, Bugajski J, Gaida T, Lemire RJ, Preis W (2005) Chemical Thermodynamics of Nickel. Elsevier, Amsterdam, The Netherlands

37. Mompeán FJ, Wanner H (2003) Radiochim Acta 91:617

38. Hummel W, Berner U, Curti E, Pearson FJ, Thoenen T (2002) Radiochim Acta 90:805

39. Hummel W (2005) Pure Appl Chem 77:631

40. Hummel W, Anderegg G, Puigdomènech I, Rao L, Tochiyama O (2005) Chemical Thermodynamics of Compounds and Complexes of U, Np, Pu, Am, Tc, Zr, $\mathrm{Ni}$, and Se with Selected Organic Ligands. Elsevier, Amsterdam, The Netherlands

41. Hummel W, Anderegg G, Puigdomènech I, Rao L, Tochiyama O (2005) Radiochim Acta 93:719

42. Hummel W, Puigdomènech I, Rao L, Tochiyama O (2007) C R Chimie 10:948

43. Hummel W (1992) Radiochim Acta 58/59:453

44. Van Loon LR, Hummel W (1999) Nucl Technol 128:359
45. Hummel W, Van Loon LR (1999) Nucl Technol 128:372

46. Van Loon LR, Hummel W (1999) Nucl Technol 128:388

47. Hummel W (2004) Environ Geol 54:633

48. Hummel W (1997) Binding models for humic substances. In: Grenthe I, Puigdomènech I (eds) Modelling in Aquatic Chemistry. OECD Nuclear Energy Agency, Paris, France, $153 \mathrm{p}$

49. Tipping E (2002) Cation Binding by Humic Substances. Cambridge University Press, Cambridge, UK

50. Hummel W, Glaus MA, Van Loon LR (2000) Appl Geochem 15:975

51. Hummel W, Glaus MA, Van Loon LR (1999) Radiochim Acta 84:111

52. Glaus MA, Hummel W, Van Loon LR (1995) Environ Sci Technol 29:2159

53. Glaus MA, Hummel W, Van Loon LR (2000) Appl Geochem 15:953

54. Neck V, Kim JI (2001) Radiochim Acta 89:1 